\title{
SUSTAINABLE INFRASTRUCTURE PROJECT SELECTION BY A NEW GROUP DECISION-MAKING FRAMEWORK INTRODUCING MORAS METHOD IN AN INTERVAL TYPE 2 FUZZY ENVIRONMENT
}

\author{
Vahid MOHAGHEGHI ${ }^{1}$, Seyed Meysam MOUSAVI ${ }^{1,}$, Jurgita ANTUCHEVIČIENÉ (D) 2 , \\ Yahya DORFESHAN ${ }^{3}$ \\ ${ }^{1}$ Department of Industrial Engineering, Shahed University, Tehran, Iran \\ ${ }^{2}$ Department of Construction Management and Real Estate, Vilnius Gediminas Technical University, Vilnius, Lithuania \\ ${ }^{3}$ School of Industrial Engineering, College of Engineering, University of Tehran, Tehran, Iran
}

Received 16 February 2019; accepted 06 June 2019

\begin{abstract}
Project management is a process that is involved with making important decisions under uncertainty. In project management often the existing data is limited and vague. Sustainable project selection has a multi-criteria evaluation nature which calls for attending to various often conflicting factors under vagueness. To deal with sustainable project selection several important factors should be properly considered. In this paper, in order to provide a new multi-criteria project selection method, a novel last aggregation method is presented. This method has several main novelties. First, to address uncertainty interval type 2 fuzzy sets (IT2FSs) are used. Second, the importance of criteria is investigated by using IT2F entropy. Third, a novel index for decision making is presented that has the merits of ratio system in MOORA and COPRAS, named MORAS. Fourth, the weights of decision makers are computed according to the obtained judgments and the weights are employed to aggregate the results. Fifth, the defuzzification is carried out in the last step of the process by means of a new IT2F ranking method. To present the applicability of the method, it is used in an existing case study in the literature and the outcomes are presented.
\end{abstract}

Keywords: interval type 2 fuzzy sets (IT2FSs), decision makers' weights, entropy, last aggregation, COPRAS, MOORA, MORAS method, sustainable infrastructure project selection.

\section{Introduction}

Construction and infrastructure projects to reach their predetermined objectives over their life cycle often face many difficulties. Complexities and specific nature of construction projects should be properly managed (Taillandier et al., 2015). Construction and infrastructure projects are exposed to more risks. Such risks should be addressed in different phases of the project life cycle. In project selection, which is categorized as a strategic decision-making process, the decision maker (DM) is required to find a number of the most proper projects while considering the outcome of projects (Mavrotas, Diakoulaki, \& Kourentzis, 2008; Pires, Ferreira, Jalali, \& Chang, 2018). There are several factors that complicate this process. One of the factors that improves the complexity of project evaluation methods is uncertainty (Mohagheghi, Mousavi, \& Vahdani, 2016).

On the other hand, the DMs should attend to issues like inadequate information and deficiency of expertise
(Hsu, 2014). Fuzzy sets theory as an uncertainty modeling tool has been employed in many studies to deal with the vagueness of projects (Zolfaghari \& Mousavi, 2018; Davoudabadi, Mousavi, Šaparauskas, \& Gitinavard, 2019; Dorfeshan \& Mousavi, 2019). Even though it is accepted that it is impossible to gain effective project management without proper uncertainty management, employing more sophisticated tools prior to achieving practical outcomes is required (Atkinson, Crawford, \& Ward, 2006; Gitinavard, Foroozesh, Mousavi, \& Mohagheghi, 2018). In other words, when it comes to uncertain modeling tools, it is necessary to use powerful tools. Classic fuzzy sets despite their ability to express uncertainty have several shortcomings. One of its shortcomings is when a DM has to express an exact opinion in a number in interval $[0,1]$ (Mohagheghi et al., 2016; Mousavi, 2018).

One of the recently applied methods in project evaluation is using type 2 fuzzy sets (T2FSs) to express

\footnotetext{
*Corresponding author. E-mail:sm.mousavi@shahed.ac.ir
} 
uncertainty. T2FS include measures of fuzzy membership functions (FMFs) as known as membership of membership. In T2FSs contrary to type-1 fuzzy sets, each element includes membership degrees denoted by fuzzy sets in $[0,1]$, instead of a crisp value in $[0,1]$. Likewise, type- 2 FMFs are three-dimensional. In other words, they attend to possibilities by employing the weights in the membership scope. This third modern aspect provides different design amounts of freedom for addressing secondary uncertainties (Mendel, 2003; Maity \& Sil, 2009). T2FSs have been recently successfully used in project management. For instance, Kiliç and Kaya (2015) introduced a method of project evaluation based on T2FSs. Oztaysi (2015) used interval type 2 fuzzy sets (IT2FSs) in project selection under uncertainty. Mohagheghi, Mousavi, and Vahdani (2017a) used IT2FSs to model project cash flow with uncertain time and cost. Moreover, IT2FSs were used to assess research and development $(\mathrm{R} \& \mathrm{D})$ projects and $\mathrm{R} \& \mathrm{D}$ project portfolio selection (Mohagheghi, Mousavi, Vahdani, \& Shahriari, 2017c). IT2FSs were also applied in new product development project screening (Chiao, 2014).

In recent years, project selection has been the subject of many studies. For instance, Rathi, Khanduja, and Sharma (2015) presented a TOPSIS based method to address project selection. Grady, He, and Peeta (2015) developed a project selection method by using the analytic network process (ANP). Another utilization of multi-criteria decision making (MCDM) tools in project selection was introduced by the research of Tavana, Keramatpour, Santos-Arteaga, and Ghorbaniane (2015). In that research, data envelopment analysis (DEA) and TOPSIS were used with integer programming to address project selection. Parvaneh and El-Sayegh (2016) applied the analytic hierarchy process (AHP) and linear programming to propose a new model for project selection.

What can be gained from a briefing of the above studies and similar other studies is that project selection has been studied by many scholars over the years and using MCDM methods is one of the most applicable approaches in this field. Despite this application, there are important issues in this decision-making process that should be addressed, but unfortunately, are not yet fully explored. Matters, like using proper uncertainty modeling tools, addressing the weight of DMs, computing the weight of criteria, aggregating in a way that avoids information loss and keeping the uncertain nature of decision-making data in the process are some of the other issues that are new to this problem.

As it was mentioned earlier, several decision-making approaches have been used to address project selection. One decision-making method that is new in the project environment is multi-objective optimization on the basis of ratio analysis (MOORA) method (Brauers \& Zavadskas, 2006). In the last decade, this method has been used in many applications. For example, it was used in the manufacturing environment (Chakraborty, 2011; Chatterjee, Athawale, \& Chakraborty, 2011), in construction (Kracka, Brauers, \& Zavadskas, 2010) and project man- agement (Brauers \& Zavadskas, 2010). When considering the procedure applied to find the best alternatives, it will be observed that the MOORA method can be categorized as a method that is between the well-known SAW method and the most widely used TOPSIS method. In other words, this method is efficient and also easy to use (Stanujkic, Magdalinovic, Stojanovic, \& Jovanovic, 2012). Brauers, Zavadskas, Turskis, and Antucheviciene (2006) applied the MOORA method to address construction decision-making problems. MOORA is also developed into the MULTIMOORA method which is also another well-known and practical method. A recent review of this method shows that this method is highly applicable in many fields (Hafezalkotob, Hafezalkotob, Liao, \& Herrera, 2019). Another method that can be used to improve project related decision making is the complex proportional assessment (COPRAS) method (Zavadskas, Kaklauskas, \& Sarka, 1994). This method is plain in practice and requires small computation time while set side by side of other multi-criteria methods such as the technique for order of preference by similarity to ideal solution (TOPSIS) and the AHP. It is able to address the quantitative and qualitative criteria in one appraisal. It can be employed to approximate the utility degree of candidates. It can further evaluate both positive and negative evaluation criteria separately (Mulliner, Smallbone, \& Maliene, 2013). The COPRAS method has been used by Liou, Tamošaitiene, Zavadskas, and Tzeng (2016) to address green supply chain management problems.

Moreover, Amoozad Mahdiraji, Arzaghi, Stauskis, and Zavadskas (2018) introduced a novel COPRAS method based on the best-worst multi-criteria decision-making method. Kildiené, Kaklauskas, and Zavadskas (2011) applied the COPRAS method to address decision making in the construction sector. Another example of such application is the study of Zavadskas, Kaklauskas, Turskis, Tamosaitiene, and Kalibatas (2011), in which the COPRAS was used to address decision making in housing decision makings. COPRAS and MOORA were applied in strategic decision making by Akhavan, Barak, Maghsoudlou, and Antuchevičienè (2015). Umer, Hewage, Haider, and Sadiq (2016) addressed sustainability in roadway projects by presenting a hierarchical framework that developed the sustainability objective indices through aggregating proper indicators while employing a fuzzy synthetic evaluation technique. Kivilä, Martinsuo, and Vuorinen (2017) with the goal of finding the control methods applied by project organizations for sustainable project management carried out a qualitative case study on a large infrastructure project which involved multiple stakeholders in an alliance contract. Zhang and Yang (2018) addressed sustainability in construction projects by addressing the challenges in sustainable highway infrastructure. Sierra, Yepes, and Pellicer (2018) addressed multi-criteria assessment methods of social sustainability by reviewing the published studies. Their review showed that mobility and access, safety and local development were the most commonly employed criteria. Moreover, they figured out that the AHP and 
simple additive weighting (SAW) methods had the highest rate of application in this field. Erdogan, Šaparauskas, and Turskis (2019) introduced a set of criteria to form a decision-making model for construction management. In this study, the AHP method and Expert Choice computer program were applied. Zolfani, Pourhossein, Yazdani, and Zavadskas (2019) introduced a decision-making method to address sustainability in construction projects. In their method, step-wise weight assessment ratio analysis (SWARA) and COPRAS were applied. Mathiyazhagan, Gnanavelbabu, and Lokesh Prabhuraj (2019) introduced a three-phase methodology to evaluate construction materials. In the first phase, the criteria and the alternatives were identified. In the second phase, the best worst methodology (BWM) was used to evaluate the importance of criteria. Finally, the third phase ranked materials. Ebrahiminejad, Shakeri, Ardeshir, and Zarandi (2018) introduced an object-oriented model to address construction method selection by employing fuzzy information.

It can be concluded from the above that using effective decision-making approaches can improve project decision-making methods. Moreover, using T2FSs for project evaluation and selection is a recent trend that has proven to be successful in dealing with ever-increasing uncertainty and complexity of project environments. Therefore, given the presented review of recent studies the main motivations for presenting this paper are as follows:

Using multi-attribute decision making (MADM) methods for sustainable evaluation is a practical approach. However, it is possible to improve the effectiveness of the decisions by presenting novel MADM methods that are the result of combining two or more MADM methods. This would provide the method with the benefits of each of the methods. For example, the COPRAS and ratio system of MOORA have their advantages that can be employed to enhance the decision making. Thus, this paper presents a novel way of project evaluation based on the notion of IT2F uncertainty. The method uses the advantages of the COPRAS and ratio system of MOORA. Another motivation for this study is the importance of addressing proper weighting methods for evaluation criteria. One practical approach that has not been employed in this field of practical decision making is entropy. Adequately attending to the importance of DMs in the process is another main motivation for presenting this paper. The obtained judgments are utilized to compute the weight of each DM. A weak point in most of the fuzzy studies is that the fuzziness of data is often lost in the initial steps of the methods. As a result, this was a motivation to present a technique that saved the fuzziness of decision making data until the last step. Finally, it is worth mentioning that another motivation of this study is the first aggregation nature of similar studies which results in loss of data. As a result, the introduced method is the last aggregation which means the information loss in the aggregation process is reduced. This method is utilized in a case study where mega construction projects are evaluated. In conclusion, the main characteristics of this study are as presented as:
- IT2FSs are used to address uncertainty of projects.

- A novel decision-making index established on the concepts of the MOORA and the COPRAS under IT2FS uncertainty is introduced.

- A new path in dealing with weights of DMs is presented.

- IT2F entropy is employed to cope with weights of criteria.

- The method is last aggregation and averts loss of knowledge.

- Defuzzification is carried out in the last step of the process.

- A novel IT2F ranking way is used to rank the fuzzy evaluation scores.

The remaining is structured as follows. Preliminary embraces the basic awareness of IT2FSs. The introduced way of sustainable infrastructure project evaluation is presented next. The utilization of the method in an existing case study in the literature is presented, and then, discussions of results are provided. Finally, the paper is wrapped up in the conclusion section.

\section{Preliminary knowledge of interval type 2 fuzzy sets}

Type-2 fuzzy sets are most advantageous when denoting the perfect membership function of a fuzzy set becomes complicated (Mendel, 2007). General type-2 fuzzy sets are computationally demanding, and this aspect has made the utilization of interval type-2 FSs more common (Kiliç \& Kaya, 2015; Haghighi, Mousavi, Antucheviciene, \& Mohagheghi, 2019; Haghighi, Mousavi, \& Mohagheghi, 2019; Dorfeshan, Mousavi, Mohagheghi, \& Vahdani, 2018; Dorfeshan \& Mousavi, 2019; Moradi, Mousavi, \& Vahdani, 2018). The main goal of this section is to provide the basic knowledge of interval type-2 fuzzy sets.

Definition 1. A type-2 membership function $\mu_{\widetilde{\widetilde{A}}}$ is employed to present a type-2 FS $\widetilde{\widetilde{A}}$ in the universe of discourse X. This set is presented as follows (Mendel, John, \& Liu, 2006; Mendel, 2007):

$$
\begin{aligned}
& \widetilde{\widetilde{A}}=\left\{\left((x, u), \mu_{\widetilde{A}}(x, u)\right) \mid \forall x \in X,\right. \\
& \left.\forall u \in p_{x} \subseteq[0,1], 0 \leq \mu_{\widetilde{A}}(x, u) \leq 1\right\},
\end{aligned}
$$

where: $p_{x}$ denotes an interval in $[0,1]$. It is possible to express $\widetilde{\widetilde{A}}$ as following:

$$
\widetilde{\widetilde{A}}=\int_{x \in X} \int_{u \in J_{x}} \frac{\mu \widetilde{\widetilde{A}}(x, u)}{(x, u)},
$$

where: $J_{x} \subseteq[0,1]$ and $\iint$ displays union over the entire allowed $x$ and $u$.

Definition 2. If in $\widetilde{\widetilde{A}}$ the entire $\mu_{\tilde{A}}(x, u)=1$, then $\widetilde{\widetilde{A}}$ is characterized as an interval type- 2 fuzzy set. This as an exclusive condition of a type-2 fuzzy set is illustrated as follows (Mendel, 2007):

$$
\widetilde{\widetilde{A}}=\int_{x \in X} \int_{u \in J_{x}} \frac{1}{(x, u)},
$$

where: $J_{x} \subseteq[0,1]$. 
Definition 3. When upper membership function (UMF) and lower membership function (LMF) of an interval type-2 fuzzy number are characterized as trapezoidal fuzzy numbers, the number becomes a trapezoidal interval type-2 fuzzy number. Such a number like $A$ is presented in Eq. (4) (Chen \& Lee, 2010):

$A=\left(A^{U}, A^{L}\right)=\left(\begin{array}{l}\left(a_{1}^{U}, a_{2}^{U}, a_{3}^{U}, a_{4}^{U} ; H_{1}\left(A^{U}\right), H_{2}\left(A^{U}\right)\right), \\ \left(a_{1}^{L}, a_{2}^{L}, a_{3}^{L}, a_{4}^{L} ; H_{1}\left(A^{L}\right), H_{2}\left(A^{L}\right)\right)\end{array}\right),(4)$

where: $A^{U}$ and $A^{L}$ denote the UMF and LMF of $A$; respectively, and $H_{j}\left(A^{U}\right)$ and $H_{j}\left(A^{L}\right)$ $\left(H_{j}\left(A^{U}\right) \in[0,1], H_{j}\left(A^{L}\right) \in[0,1], j=1,2\right)$ express the membership degrees of the corresponding elements $a_{j+1}^{L}$ and $a_{j+1}^{U}$, respectively. Figure 1 shows $A$.

For $A_{1}$ and $A_{2}$ as presented in Eqs (5) and (6) the arithmetic operations are defined.

$A_{1}=\left(A_{1}^{U}, A_{1}^{L}\right)=\left(\begin{array}{l}\left(a_{11}^{U}, a_{12}^{U}, a_{13}^{U}, a_{14}^{U} ; H_{1}\left(A_{1}^{U}\right), H_{2}\left(A_{1}^{U}\right)\right), \\ \left(a_{11}^{L}, a_{12}^{L}, a_{13}^{L}, a_{14}^{L} ; H_{1}\left(A_{1}^{L}\right), H_{2}\left(A_{1}^{L}\right)\right)\end{array}\right) ;$

$A_{2}=\left(A_{2}^{U}, A_{2}^{L}\right)=\left(\begin{array}{l}\left(a_{21}^{U}, a_{22}^{U}, a_{23}^{U}, a_{24}^{U} ; H_{1}\left(A_{2}^{U}\right), H_{2}\left(A_{2}^{U}\right)\right), \\ \left(a_{21}^{L}, a_{22}^{L}, a_{23}^{L}, a_{24}^{L} ; H_{1}\left(A_{2}^{L}\right), H_{2}\left(A_{2}^{L}\right)\right)\end{array}\right)$.

The following shows the addition operation $(\mathrm{Hu}$, Zhang, Chen, \& Liu, 2013).

$A_{1} \oplus A_{2}=\left(A_{1}^{U}, A_{1}^{L}\right)+\left(A_{2}^{U}, A_{2}^{L}\right)=$

$\left[\left(a_{11}^{U}+a_{21}^{U}, a_{12}^{U}+a_{22}^{U}, a_{13}^{U}+a_{23}^{U}, a_{14}^{U}+a_{24}^{U} ; H_{1}\left(\widetilde{A}_{1}^{U}\right)+H_{1}\left(\widetilde{A}_{2}^{U}\right)-\right.\right.$ $\left.H_{1}\left(\widetilde{A}_{1}^{U}\right) \cdot H_{1}\left(\widetilde{A}_{2}^{U}\right), H_{1}\left(\widetilde{A}_{1}^{U}\right)+H_{2}\left(\widetilde{A}_{2}^{U}\right)-H_{2}\left(\widetilde{A}_{1}^{U}\right) \cdot H_{2}\left(\widetilde{A}_{2}^{U}\right)\right)$, $\left(a_{11}^{L}+a_{21}^{L}, a_{12}^{L}+a_{22}^{L}, a_{13}^{L}+a_{23}^{L}, a_{14}^{L}+a_{24}^{L} ;\right.$

$H_{1}\left(\widetilde{A}_{1}^{L}\right)+H_{1}\left(\widetilde{A}_{2}^{L}\right)-H_{1}\left(\widetilde{A}_{1}^{L}\right) . H_{1}\left(\widetilde{A}_{2}^{L}\right), H_{1}\left(\widetilde{A}_{1}^{L}\right)+H_{2}\left(\widetilde{A}_{2}^{L}\right)-$ $\left.\left.H_{2}\left(\widetilde{A}_{1}^{L}\right) \cdot H_{2}\left(\widetilde{A}_{2}^{L}\right)\right)\right]$.

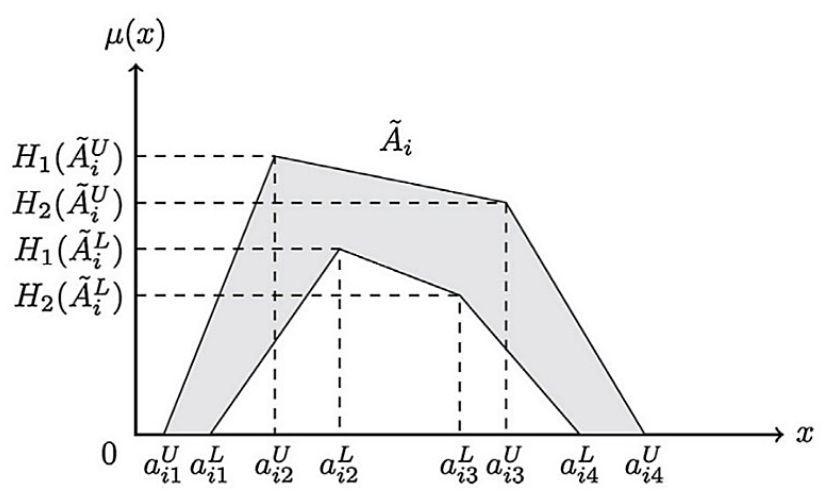

Figure 1. A trapezoidal interval type-2 fuzzy set 2013):

The following is applicable for subtraction (Hu et al.,

$$
\begin{aligned}
& A_{1} \ominus A_{2}=\left(A_{1}^{U}, A_{1}^{L}\right)-\left(A_{2}^{U}, A_{2}^{L}\right)= \\
& {\left[\left(a_{11}^{U}-a_{24}^{U}, a_{12}^{U}-a_{23}^{U}, a_{13}^{U}-a_{22}^{U}, a_{14}^{U}-a_{21}^{U} ;\right.\right.} \\
& H_{1}\left(\widetilde{A}_{1}^{U}\right)+H_{1}\left(\widetilde{A}_{2}^{U}\right)-H_{1}\left(\widetilde{A}_{1}^{U}\right) \cdot H_{1}\left(\widetilde{A}_{2}^{U}\right), \\
& \left.H_{2}\left(\widetilde{A}_{1}^{U}\right)+H_{2}\left(\widetilde{A}_{2}^{U}\right)-H_{2}\left(\widetilde{A}_{1}^{U}\right) \cdot H_{2}\left(\widetilde{A}_{2}^{U}\right)\right), \\
& \left(a_{11}^{L}-a_{24}^{L}, a_{12}^{L}-a_{23}^{L}, a_{13}^{L}-a_{22}^{L}, a_{14}^{L}-a_{21}^{L} ;\right. \\
& H_{1}\left(\widetilde{A}_{1}^{U}\right)+H_{1}\left(\widetilde{A}_{2}^{U}\right)-H_{1}\left(\widetilde{A}_{1}^{U}\right) \cdot H_{1}\left(\widetilde{A}_{2}^{U}\right), \\
& \left.\left.H_{2}\left(\widetilde{A}_{1}^{U}\right)+H_{2}\left(\widetilde{A}_{2}^{U}\right)-H_{2}\left(\widetilde{A}_{1}^{U}\right) \cdot H_{2}\left(\widetilde{A}_{2}^{U}\right)\right)\right] .
\end{aligned}
$$

The following is used for the multiplication operation (Hu et al., 2013):

$$
\begin{aligned}
& A_{1} \otimes A_{2}=\left(A_{1}^{U}, A_{1}^{L}\right) \otimes\left(A_{2}^{U}, A_{2}^{L}\right)= \\
& \left(\begin{array}{c}
\left(x_{11}^{U}, x_{12}^{U}, x_{13}^{U}, x_{14}^{U} ; H_{1}\left(A_{1}^{U}\right) \cdot H_{1}\left(A_{2}^{U}\right), H_{2}\left(A_{1}^{U}\right) \cdot H_{2}\left(A_{2}^{U}\right)\right), \\
\left(x_{11}^{L}, x_{12}^{L}, x_{13}^{L}, x_{14}^{L} ; H_{1}\left(A_{1}^{L}\right) \cdot H_{1}\left(A_{2}^{L}\right), H_{2}\left(A_{1}^{L}\right) \cdot H_{2}\left(A_{2}^{L}\right)\right)
\end{array}\right),
\end{aligned}
$$

where:

$x_{1 i}^{T}=\min \left(a_{1 i}^{T} a_{2 i}^{T}, a_{1 i}^{T} a_{2(5-i)}^{T}, a_{1(5-i)}^{T} a_{2 i}^{T}, a_{1(5-i)}^{T} a_{2(5-i)}^{T}\right)$,

$T \in\{U, L\}, i \in\{1,2\}$;

$x_{1 j}^{T}=\min \left(a_{1(5-j)}^{T} a_{2(5-j)}^{T}, a_{1(5-j)}^{T} a_{2 j}^{T}, a_{1 j}^{T} a_{2(5-j)}^{T}, a_{1 j}^{T} a_{2 j}^{T}\right)$,

$T \in\{U, L\}, j \in\{3,4\}$.

The following presents the multiplication operation when a crisp number like $(\lambda)$ involved (Hu et al., 2013):

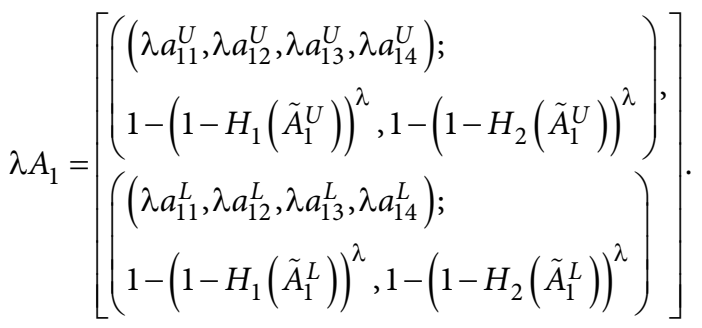

The following presents the operation of division by a nonzero number like $(k)$ :

if $k>0$

$$
A_{1} / k=\left(\begin{array}{l}
\left(a_{11}^{U} / k, a_{12}^{U} / k, a_{13}^{U} / k, a_{14}^{U} / k\right) ; H_{1}\left(\tilde{A}_{1}^{U}\right), H_{2}\left(\tilde{A}_{1}^{U}\right), \\
\left(a_{11}^{L} / k, a_{12}^{L} / k, a_{13}^{L} / k, a_{14}^{L} / k\right) ; H_{1}\left(\tilde{A}_{1}^{L}\right), H_{2}\left(\tilde{A}_{1}^{L}\right)
\end{array}\right) ;
$$

if $k<0$

$$
A_{1} / k=\left(\begin{array}{l}
\left(a_{14}^{U} / k, a_{13}^{U} / k, a_{12}^{U} / k, a_{11}^{U} / k\right) ; H_{1}\left(\tilde{A}_{1}^{U}\right), H_{2}\left(\tilde{A}_{1}^{U}\right), \\
\left(a_{14}^{L} / k, a_{13}^{L} / k, a_{12}^{L} / k, a_{11}^{L} / k\right) ; H_{1}\left(\tilde{A}_{1}^{L}\right), H_{2}\left(\tilde{A}_{1}^{L}\right)
\end{array}\right) .
$$


Eventually, the following is applicable for the division operation (Chen \& Lee, 2010):

$A_{1} \oslash A_{2}=\left(A_{1}^{U}, A_{1}^{L}\right) \oslash\left(A_{2}^{U}, A_{2}^{L}\right)=$
$\left(\begin{array}{c}\left(Y_{11}^{U}, Y_{12}^{U}, Y_{13}^{U}, Y_{14}^{U} ; H_{1}\left(A_{1}^{U}\right) \cdot H_{1}\left(A_{2}^{U}\right), H_{2}\left(A_{1}^{U}\right) \cdot H_{2}\left(A_{2}^{U}\right)\right), \\ \left(Y_{11}^{L}, Y_{12}^{L}, Y_{13}^{L}, Y_{14}^{L} ; H_{1}\left(A_{1}^{L}\right) \cdot H_{1}\left(A_{2}^{L}\right), H_{2}\left(A_{1}^{L}\right) \cdot H_{2}\left(A_{2}^{L}\right)\right)\end{array}\right)$,

where:

$Y_{1 i}^{T}=\min \left(a_{1 i}^{T} / a_{2 i}^{T}, a_{1 i}^{T} / a_{2(5-i)}^{T}, a_{1(5-i)}^{T} / a_{2 i}^{T}, a_{1(5-i)}^{T} / a_{2(5-i)}^{T}\right)$,

$T \in\{U, L\}, i \in\{1,2\}$;

$x_{1 j}^{T}=\min \left(a_{1(5-j)}^{T} / a_{2(5-j)}^{T}, a_{1(5-j)}^{T} / a_{2 j}^{T}, a_{1 j}^{T} / a_{2(5-j)}^{T}, a_{1 j}^{T} / a_{2 j}^{T}\right)$,

$T \in\{U, L\}, j \in\{3,4\}$.

\section{Proposed methodology}

In this part of the paper, a novel way of decision making under IT2F uncertainty is presented to be utilized in project selection. The method follows a last aggregation approach which indicates that in the process information loss is averted. Moreover, the fuzziness of the data is saved, and defuzzification is carried out in the last step of the process by using a new fuzzy ranking method. In this method, after gathering and normalizing the judgments of DMs, IT2F entropy is utilized to investigate the weight of evaluation criteria. Then, a new ranking index that is composed of ratio system of the MOORA and the COPRAS method is used to rank the alternatives for each DM. Since this decision making index applies the principles of both methods it is named MORAS to show that it is based on the two well-known methods of the MOORA and the COPRAS method. To aggregate the results, since each DM has his/her own level of importance, a novel way is employed to calculate the importance of each DM and the resulting weights are used to aggregate the rankings. Finally, since the values are all fuzzy, the final step of the process is a defuzzification step that ranks the alternatives based on a new IT2F ranking method. To provide a better understanding of the method, Figure 2 is presented. The procedure of the method is as follows:

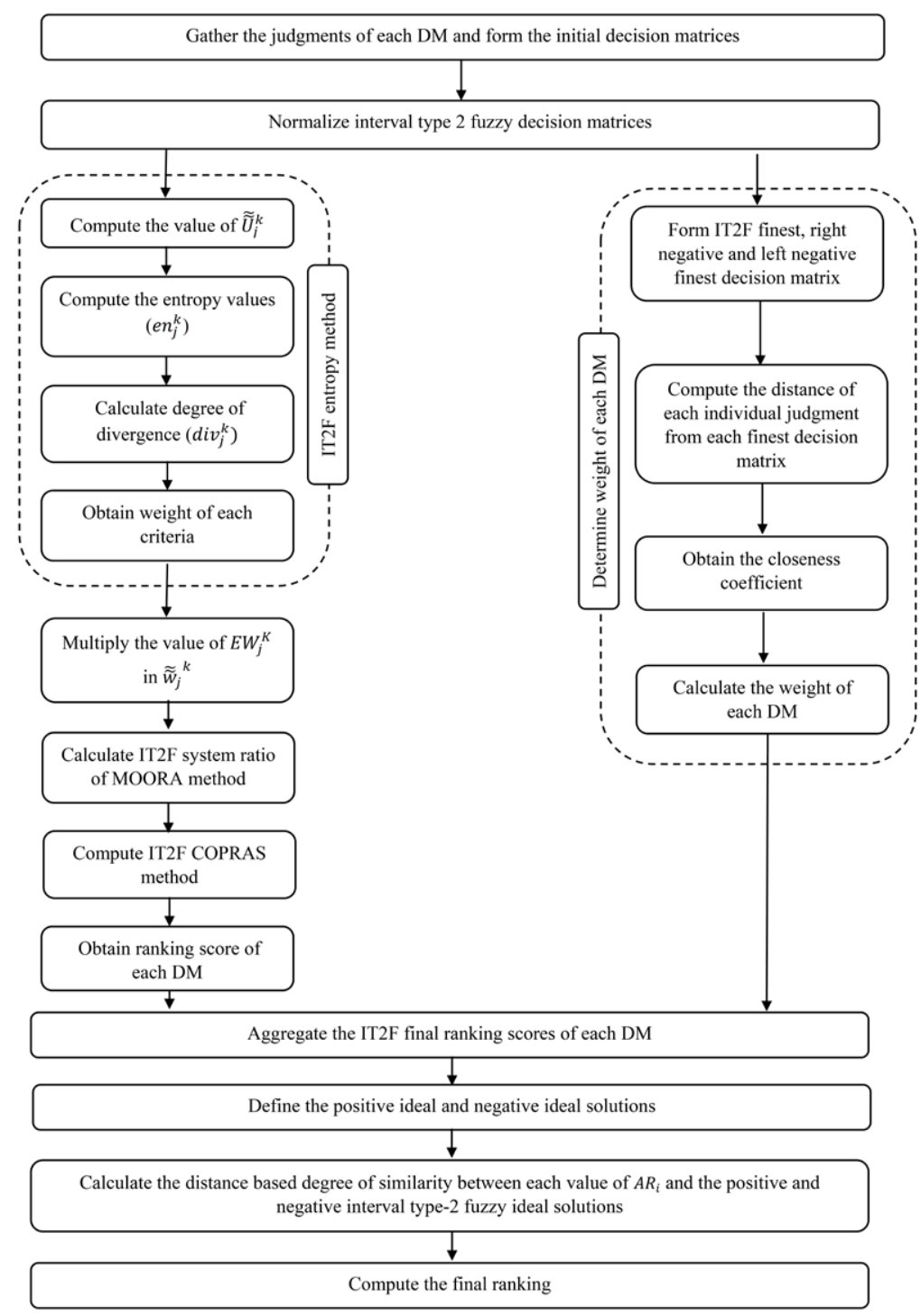

Figure 2. Visual presentation of the presented method 
1. Obtain the knowledge of each DM and make the basic decision matrices:

$$
\begin{aligned}
& \widetilde{\widetilde{D}}_{K}=\left(\widetilde{\widetilde{D}}_{i j}^{K}\right)_{m \times n}=\left[\begin{array}{ccc}
\widetilde{\widetilde{D}}_{11}^{K} & \ldots & \widetilde{\widetilde{D}}_{1 n}^{K} \\
\vdots & \ddots & \vdots \\
\widetilde{\widetilde{D}}_{m 1}^{K} & \cdots & \widetilde{\widetilde{D}}_{m n}^{K}
\end{array}\right] ; \\
& \widetilde{\widetilde{W}}_{K}=\left(\begin{array}{cc}
\widetilde{\widetilde{w}}_{1} k \widetilde{\widetilde{w}}_{2}{ }^{k}, \ldots, \widetilde{\widetilde{w}}_{n}^{k} \\
w^{k}
\end{array}\right), K \in T,
\end{aligned}
$$

where: $\widetilde{D}_{K}$ denotes the decision matrix and $\widetilde{W}_{K}$ presents the weight of criteria; $n$ shows the figure of criteria; $m$ expresses figure of compared candidates and $T$ stands for the body of DMs.

2. Compute the normalized decision matrix $(\widetilde{N D})$ by the means of the following Eqs:

$$
\begin{aligned}
& \widetilde{\widetilde{N D M}}=\left[\begin{array}{ccc}
\widetilde{\widetilde{N D}}_{11} & \cdots & \widetilde{\widetilde{N D}}_{1 n} \\
\vdots & \ddots & \vdots \\
\widetilde{\widetilde{N D}}_{m 1} & \cdots & \widetilde{\widetilde{N D}}_{m n}
\end{array}\right] \\
& {\widetilde{\overline{N D M}_{i j}}}_{=}=\left(\begin{array}{l}
\left(\frac{d_{i j_{1}}^{U}}{d^{\star}}, \frac{d_{i j 2}^{U}}{d^{\star}}, \frac{d_{i j_{3}}^{U}}{d^{\star}}, \frac{d_{i j_{4}}^{U}}{d^{\star}} ; H_{1}\left(\tilde{D}_{i j}^{U}\right), H_{2}\left(\tilde{D}_{i j}^{U}\right)\right), \\
\left(\frac{d_{i j 1}{ }^{L}}{d^{\star}}, \frac{d_{i j 2}{ }^{L}}{d^{\star}}, \frac{d_{i j 3}{ }^{L}}{d^{\star}}, \frac{d_{i j 4}{ }^{L}}{d^{\star}} ; H_{1}\left(\tilde{D}_{i j}^{L}\right), H_{2}\left(\tilde{D}_{i j}^{L}\right)\right)
\end{array}\right) \\
& i=1,2, \ldots, n, j \in B \\
& \widetilde{\overline{N D M}}_{i j}=\left(\begin{array}{c}
\left(\begin{array}{l}
Y_{11}^{U}, Y_{12}^{U}, Y_{13}^{U}, Y_{14}^{U} ; H_{1}\left(A_{1}^{U}\right) . \\
H_{1}\left(A_{2}^{U}\right), H_{2}\left(A_{1}^{U}\right) \cdot H_{2}\left(A_{2}^{U}\right)
\end{array}\right), \\
\left(\begin{array}{c}
X_{11}^{L}, X_{12}^{L}, X_{13}^{L}, X_{14}^{L} ; H_{1}\left(A_{1}^{L}\right) . \\
H_{1}\left(A_{2}^{L}\right), H_{2}\left(A_{1}^{L}\right) \cdot H_{2}\left(A_{2}^{L}\right)
\end{array}\right)
\end{array}\right),
\end{aligned}
$$

where: $Y_{1 i}^{T}=\min \left(d^{-} / d_{i j l}^{T}, d^{-} / d_{i j l(5-l)}^{T}, d^{-} / a_{i j l}^{T}, d^{-} / a_{2(5-l)}^{T}\right)$, $T \in\{U, L\}, l \epsilon\{1,2\}$

$x_{1 j}^{T}=\min \left(d^{-} / d_{2(5-v)}^{T}, d^{-} / d_{2 v}^{T}, d^{-} / d_{2(5-v)}^{T}, d^{-} / d_{2 v}^{T}\right)$,

$T \in\{U, L\}, v \in\{3,4\}$

$i=1,2, \ldots, n, j \epsilon C$

where $B$ stands for the set of benefit and $C$ stands for the set of cost criteria. $d^{\star}$ and $d^{-}$are computed as follows:

$$
\begin{aligned}
& d^{\star}=\max _{i}\left(d_{i j}\right)_{4}^{U} ; \\
& d^{-}=\min _{i}\left(d_{i j}\right)_{1}^{U} .
\end{aligned}
$$

3. Compute the entropy of decision-making criteria by following this step. To further address the importance of each criterion, the perception of entropy is utilized to calculate fuzziness of each evaluation criterion. The process is as follows (Zamri \& Abdullah, 2013):
3.1. Compute the value of $\widetilde{\widetilde{U}}_{j}^{k}$ as presented:

$$
\widetilde{\widetilde{U}}_{j}^{k}=\left(\tilde{U}_{j}^{k, U}, \tilde{U}_{j}^{k, L}\right)=\left[\left[\frac{\varphi_{j}^{k}}{\sum_{j=1}^{n} \varphi_{j}^{k}}\right]^{L},\left[\frac{\varphi_{j}^{k}}{\sum_{j=1}^{n} \varphi_{j}^{k}}\right]^{U}\right]
$$

$\tilde{\varphi}_{j}^{k, L}=\frac{\sqrt{\left.\sum_{j=1}^{n}\left[\left(w_{1 j, l}^{k, \text { near }}-w_{1 j, l}^{k}\right)^{2}+\left(w_{2 l}^{k, \text { near }}-w_{2 j, l}^{k}\right)^{2, \text { near }}-w_{3 j, l}^{k}\right)^{2}+\left(w_{4 l}^{k, \text { near }}-w_{4 j, l}^{k}\right)^{2}\right]}}{\sqrt{\sum_{j=1}^{n}\left[\left(w_{1 j, l}^{k, f a r}-w_{1 j, l}^{k}\right)^{2}+\left(w_{2 l}^{k, f a r}-w_{2 j, l}^{k}\right)^{2}+\right]}} ;$

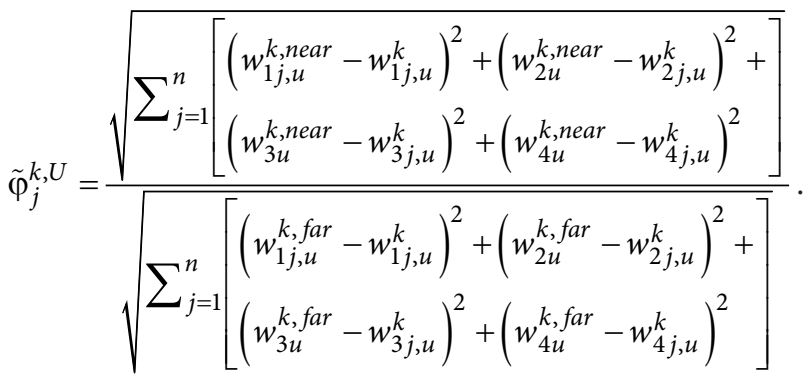

$\varphi_{j}^{k}=\left(\tilde{\varphi}_{j}^{k, L}, \tilde{\varphi}_{j}^{k, U}\right)$

3.2. Compute the entropy values $\left(e n_{j}^{k}\right)$ by using the following:

$$
\begin{aligned}
& e n_{j}^{k}=\left(e n_{j}^{k, L}, e n_{j}^{k, U}\right)= \\
& {\left[\left[-P \sum_{j=1}^{n} U_{j}^{k, l} \ln U_{j}^{k, L}\right]^{L},\left[-P \sum_{j=1}^{n} U_{j}^{k, U} \ln U_{j}^{k, U}\right]^{U}\right]}
\end{aligned}
$$

$P$ is a constant set as $(\ln (m))^{-1}$.

3.3. The degree of divergence $\left(d i v_{j}^{k}\right)$ is figured out by employing the following:

$$
\operatorname{div}_{j}^{k}=\left(\operatorname{div}_{j}^{k, L}, \operatorname{div}_{j}^{k, U}\right)=\left(\begin{array}{l}
\left(1-\left[-P \sum_{j=1}^{n} U_{j}^{k, l} \ln U_{j}^{k, L}\right]^{L}\right)^{L}, \\
\left(1-\left[-P \sum_{j=1}^{n} U_{j}^{k, l} \ln U_{j}^{k, L}\right]^{U}\right)^{U}
\end{array}\right)
$$

3.4. Higher values of $d i v_{j}^{k}$ denote more importance for the criterion $j$ in the decision making process. The weight of each criterion can be computed by the following Eqs: 


$$
\begin{aligned}
& E W_{j}^{K}=\left(\left(E W_{j}^{K, L}+E W_{j}^{K, U}\right) / 2\right)= \\
& \left(\left[\frac{\left[1-\left[-P \sum_{j=1}^{n} U_{j}^{k, l} \ln U_{j}^{k, L}\right]^{L}\right)^{L}}{\sum_{j=1}^{n}\left(1-\left[-P \sum_{j=1}^{n} U_{j}^{k, l} \ln U_{j}^{k, L}\right]^{L}\right)^{L}}+\left[\frac{\left(1-\left[-P \sum_{j=1}^{n} U_{j}^{k, u} \ln U_{j}^{k, u}\right]^{U}\right)^{U}}{\sum_{j=1}^{n}\left(1-\left[-P \sum_{j=1}^{n} U_{j}^{k, U} \ln U_{j}^{k, U}\right]^{U}\right)^{U}}\right)\right.\right.
\end{aligned}
$$

4. Obtain a new weight $\left(\widetilde{\widetilde{N W}}{ }_{j}^{k}\right)$ for selection criteria by multiplying the value of $E W_{j}^{K}$ in $\widetilde{\widetilde{w}}_{j}^{k}$. The following presents the obtained value:

$$
\widetilde{N W}_{j}^{k}=E W_{j}^{K} \times \widetilde{\widetilde{w}}_{j}^{k}
$$

5. In order to use the advantages of ratio system in the presented method, the following is proposed:

$$
S_{i B}^{k}=\sum_{j \in B}\left(\begin{array}{l}
\left(\begin{array}{l}
s b_{j 1}^{k U}, s b_{j 2}^{k U}, s b_{j 3}^{k U}, s b_{j 4}^{k U} ; H_{1}\left(N W_{j}^{k}\right) . \\
H_{1}\left(n d_{i j}^{k}\right), H_{2}\left(N W_{j}^{k}\right) \cdot H_{2}\left(n d_{i j}^{k}\right)
\end{array}\right), \\
\left(\begin{array}{l}
s b_{j 1}^{k L}, s b_{j 2}^{k L}, s b_{j 3}^{k L}, s b_{j 4}^{k L} ; H_{1}\left(N W_{j}^{k}\right) \cdot \\
H_{1}\left(n d_{i j}^{k}\right), H_{2}\left(N W_{j}^{k}\right) \cdot H_{2}\left(n d_{i j}^{k}\right)
\end{array}\right)
\end{array}\right)
$$$$
s b_{j i}^{k T}=\min \left(\begin{array}{l}
n d_{i j f}^{k T} n w_{2 f}^{T}, n d_{i j 1 f}^{k T} n w_{2(5-f)}^{T}, \\
n d_{i j 1(5-f)}^{k T} n w_{j 2 f}^{k T}, n d_{i j_{1}(5-f)}^{k T} n w_{j_{2(5-f)}}^{k T}
\end{array}\right),
$$$$
T \in\{U, L\}, f \in\{1,2\}
$$$$
s b_{1 g}^{k T}=\min \left(\begin{array}{l}
n d_{i j_{1}(5-g)^{k T}}^{n w_{j_{2(5-g}}^{k T},}, n d_{i j_{1}(5-g)}^{k T} n w_{j 2 g}^{k T}, \\
n d_{i j 1 g}^{k T} n w_{j_{2}(5-g)}^{k T}, n d_{i j 1 g}^{k T} n w_{j 2 g}^{k T}
\end{array}\right),
$$

$T \in\{U, L\}, g \in\{3,4\}$

$$
\begin{aligned}
& S_{i C}^{k}=\sum_{j \in C}\left(\begin{array}{l}
\left(\begin{array}{l}
s c_{j 1}^{k U}, s c_{j 2}^{k U}, s c_{j 3}^{k U}, s c_{j 4}^{k U} ; H_{1}\left(N W_{j}^{k}\right) \cdot \\
H_{1}\left(n d_{i j}^{k}\right), H_{2}\left(N W_{j}^{k}\right) \cdot H_{2}\left(n d_{i j}^{k}\right)
\end{array}\right), \\
\left(\begin{array}{l}
s c_{j 1}^{k L}, s c_{j 2}^{k L}, s c_{j 3}^{k L}, s c_{j 4}^{k L} ; H_{1}\left(N W_{j}^{k}\right) \cdot \\
H_{1}\left(n d_{i j}^{k}\right), H_{2}\left(N W_{j}^{k}\right) \cdot H_{2}\left(n d_{i j}^{k}\right)
\end{array}\right)
\end{array}\right), \\
& s c_{j i}^{k T}=\min \left(\begin{array}{l}
n d_{i j f}^{k T} n w_{2 f}^{T}, n d_{i j 1 f}^{k T} n w_{2(5-f)}^{T}, \\
n d_{i j 1(5-f)}^{k T} n w_{j 2 f}^{k T}, n d_{i j 1(5-f)}^{k T} n w_{j 2(5-f)}^{k T}
\end{array}\right),
\end{aligned}
$$$$
T \in\{U, L\}, f \in\{1,2\}
$$$$
s c_{1 g}^{k T}=\min \left(\begin{array}{l}
n d_{i j_{1}(5-g)}^{k T} n w_{\left.j_{2(5-g}\right)}^{k T}, n d_{i j_{1}(5-g)}^{k T} w_{j 2 g}^{k T}, \\
n d_{i j 1 g}^{k T} n w_{j_{2}(5-g)}^{k T}, n d_{i j 1 g}^{k T} n w_{j 2 g}^{k T}
\end{array}\right),
$$

$T \in\{U, L\}, g \in\{3,4\}$
$S_{i, \text { ratio system }}^{k}=$

$\sum_{j \in B}\left(\begin{array}{l}\left(\begin{array}{l}s b_{j 1}^{k U}, s b_{j 2}^{k U}, s b_{j 3}^{k U}, s b_{j 4}^{k U} ; H_{1}\left(N W_{j}^{k}\right) \cdot \\ H_{1}\left(n d_{i j}^{k}\right), H_{2}\left(N W_{j}^{k}\right) \cdot H_{2}\left(n d_{i j}^{k}\right)\end{array}\right), \\ \left(\begin{array}{l}s b_{j 1}^{k L}, s b_{j 2}^{k L}, s b_{j 3}^{k L}, s b_{j 4}^{k L} ; H_{1}\left(N W_{j}^{k}\right) \cdot \\ H_{1}\left(n d_{i j}^{k}\right), H_{2}\left(N W_{j}^{k}\right) \cdot H_{2}\left(n d_{i j}^{k}\right)\end{array}\right)\end{array}\right)-$

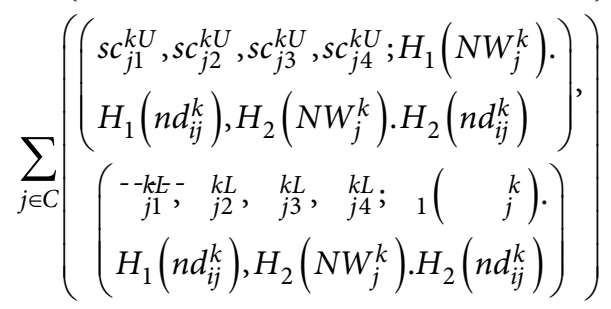

6. To use the advantages of COPRAS, the following is computed:

$$
S_{\text {Copras }}^{k}=S_{i B}^{k}+\frac{\min S_{i C}^{k} \cdot \sum_{i}\left(S_{i C}^{k}\right)}{S_{i C}^{k} \cdot \sum_{i=1}^{n} \frac{\min S_{i C}^{k}}{S_{i C}^{k}}}
$$

7. Compute the following to obtain the ranking score of each DM:

$$
\begin{aligned}
& R_{i}^{k}=\left(\gamma \left(\sum_{j \in B}\left(\begin{array}{l}
\left(s b_{j 1}^{k U}, s b_{j 2}^{k U}, s b_{j 3}^{k U}, s b_{j 4}^{k U} ;\right. \\
\left.H_{1}\left(N W_{j}^{k}\right) \cdot H_{1}\left(n d_{i j}^{k}\right), H_{2}\left(N W_{j}^{k}\right) \cdot H_{2}\left(n d_{i j}^{k}\right)\right), \\
\left(s b_{j 1}^{k L}, s b_{j 2}^{k L}, s b_{j 3}^{k L}, s b_{j 4}^{k L} ; H_{1}\left(N W_{j}^{k}\right) \cdot H_{1}\left(n d_{i j}^{k}\right),\right. \\
\left.H_{2}\left(N W_{j}^{k}\right) \cdot H_{2}\left(n d_{i j}^{k}\right)\right)
\end{array}\right)-\right.\right. \\
& \left.\sum_{j \in B}\left(\begin{array}{l}
\left(s c_{j 1}^{k U}, s c_{j 2}^{k U}, s c_{j 3}^{k U}, s c_{j 4}^{k U} ;\right. \\
\left.H_{1}\left(N W_{j}^{k}\right) \cdot H_{1}\left(n d_{i j}^{k}\right), H_{2}\left(N W_{j}^{k}\right) \cdot H_{2}\left(n d_{i j}^{k}\right)\right), \\
\left(s c_{j 1}^{k L}, s c_{j 2}^{k L}, s c_{j 3}^{k L}, s c_{j 4}^{k L} ; H_{1}\left(N W_{j}^{k}\right) \cdot H_{1}\left(n d_{i j}^{k}\right),\right. \\
\left.H_{2}\left(N W_{j}^{k}\right) \cdot H_{2}\left(n d_{i j}^{k}\right)\right)
\end{array}\right)\right)+
\end{aligned}
$$$$
\left((1-\gamma)\left(S_{i B}^{k}+\frac{\min S_{i C}^{k} \cdot \sum_{i}\left(S_{i C}^{k}\right)}{S_{i C}^{k} \cdot \sum_{i=1}^{n} \frac{\min S_{i C}^{k}}{S_{i C}^{k}}}\right)\right)
$$ 
8. Figure out the importance of DMs by the following sub-steps.

8.1. Maximum distance from the positive ideal judgment is termed negative ideal decision. This would result in two amounts of left negative ideal decision and right negative ideal decision (Yue, 2011). Consequently, the finest decision $\left(F D^{*}\right)$, the left negative finest decision $\left(F D_{l}^{-}\right)$ and the right negative finest decision $\left(F D_{r}^{-}\right)$are computable by the following Eqs:

$$
\widetilde{\widetilde{F D}}^{*}=\left[\begin{array}{ccc}
\widetilde{\widetilde{F D}}_{11}^{*} & \cdots & \widetilde{\widetilde{F D}}_{1 n}^{*} \\
\vdots & \ddots & \vdots \\
\widetilde{\widetilde{F D}}_{m 1}^{*} & \cdots & \widetilde{\widetilde{F D}}_{m n}^{*}
\end{array}\right]
$$

where: $(F D)_{i j}^{*}=$

$$
\begin{gathered}
\left(\begin{array}{l}
\left.1 / t \sum_{k=1}^{t} n d_{i j 1}^{U}, 1 / t \sum_{k=1}^{t} n d_{i j 2}^{U}, 1 / t \sum_{k=1}^{t} n d_{i j 3}^{U}, 1 / t \sum_{k=1}^{t} n d_{i j 4}^{U} ; H_{1}\left(\widetilde{N D}_{i j}^{U}\right), H_{2}\left(\widetilde{N D}_{i j}^{U}\right)\right) \\
\left(1 / t \sum_{k=1}^{t} n d_{i j 1}^{L}, 1 / t \sum_{k=1}^{t} n d_{i j 2}^{L}, 1 / t \sum_{k=1}^{t} n d_{i j 3}^{L}, 1 / t \sum_{k=1}^{t} n d_{i j 4}^{L} ; H_{1}\left(\widetilde{N D}_{i j}^{L}\right), H_{2}\left(\widetilde{N D}_{i j}^{L}\right)\right)
\end{array}\right) \\
\widetilde{\widetilde{F D}}_{L}-\left[\begin{array}{ccc}
\widetilde{\widetilde{F D}}_{l}- & \cdots & \widetilde{\widetilde{F D}}_{l 11}^{-} \\
\vdots & \ddots & \vdots \\
\widetilde{\widetilde{F D}}_{l m 1}^{-} & \cdots & \widetilde{\widetilde{F D}}_{l m n}^{-}
\end{array}\right],
\end{gathered}
$$

where: $\widetilde{\widetilde{F D}}_{l i j}^{-}=\min _{1 \leq k \leq t}\left\{\widetilde{\widetilde{N D}}_{i j}^{k}\right\}$.

$$
\widetilde{\widetilde{F D}}_{R}^{-}=\left[\begin{array}{ccc}
\widetilde{\widetilde{F D}}_{r 11}^{-} & \cdots & \widetilde{\widetilde{F D}}_{r 1 n}^{-} \\
\vdots & \ddots & \vdots \\
\widetilde{\widetilde{F D}}_{r m 1}^{-} & \cdots & \widetilde{\widetilde{F D}}_{r m n}^{-}
\end{array}\right]
$$

where: $\widetilde{\widetilde{F D}}_{r i j}^{-}=\max _{1 \leq k \leq t}\left\{\widetilde{\widetilde{N D}}_{i j}^{k}\right\}$.

8.2. The distance of each individual assessment from the ideal assessments that possess the positive, the left negative and the right negative ideal assessments are respectively denoted by $D I J_{k}^{*}, D I J_{l k}^{-}$and $D I J_{l r}^{-}$that are obtained by using the following Eqs:

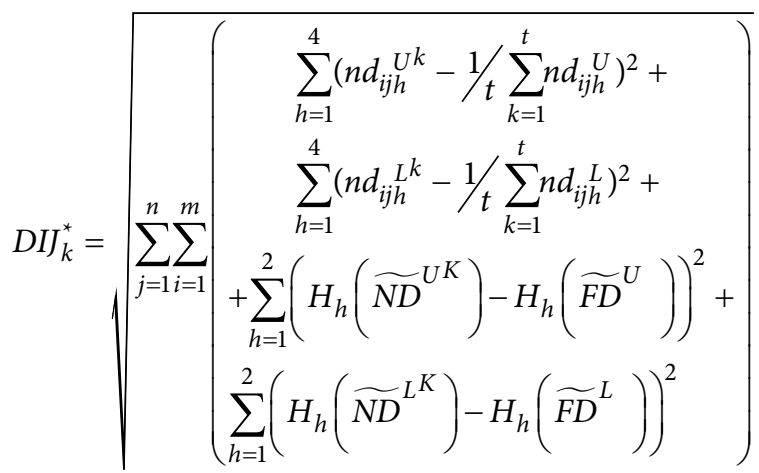

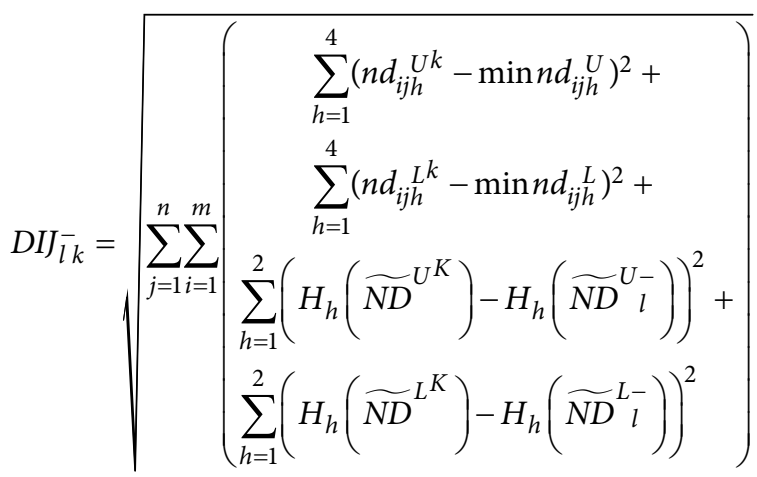

$k \in T$

$$
D I J_{l r}^{-}=\sqrt{\sum_{j=1}^{n} \sum_{i=1}^{m}\left(\begin{array}{c}
\sum_{h=1}^{4}\left(n d_{i j h}{ }^{k}-\max n d_{i j h}{ }^{U}\right)^{2}+ \\
\sum_{h=1}^{4}\left(n d_{i j h}{ }^{k}-\max n d_{i j h}{ }^{L}\right)^{2}+ \\
\left.\left.\sum_{h=1}^{2}\left(\widetilde{N D}^{U}\left(H_{h}\left(\widetilde{N D}^{L}\right)-\mathrm{H}_{h}\left(\widetilde{N D}^{U}\right) H_{h}\right)\right)^{2}+\widetilde{N D}^{L+}\right)\right)^{2}
\end{array}\right)}
$$

$k \in T$.

8.3. The obtained figure of distance is utilized to figure out the closeness coefficient of the individual assessment with respect to the ideal judgments. This figure $\left(I J C C_{k}\right)$ is obtained as:

$$
\begin{aligned}
& \mathrm{IJCC}_{k}=\frac{W E^{+} \mathrm{DIJ} J^{-}}{W E^{+} D I J^{-}+W E^{-} D I J_{k}^{*}}, K \in T \\
& D I J^{-}=\max \left[D I J_{r}^{-}, D I J_{l}^{-}\right]
\end{aligned}
$$

where: $W E^{+}$and $W E^{-}$denote the weights that reflect the importance of the two separation measures in the mind of a DM. It should be noted that $W E^{+}+W E^{-}=1,0<W E^{+}<$ 1 and $0<W E^{-}<1$.

8.4. Eventually, importance of DMs are figured out as follows:

$$
W F_{k}=\frac{I J C C_{k}}{\sum_{k=1}^{t} I J C C_{k}}, K \in T .
$$

9. Aggregate the final ranking scores of each DM by using the following:

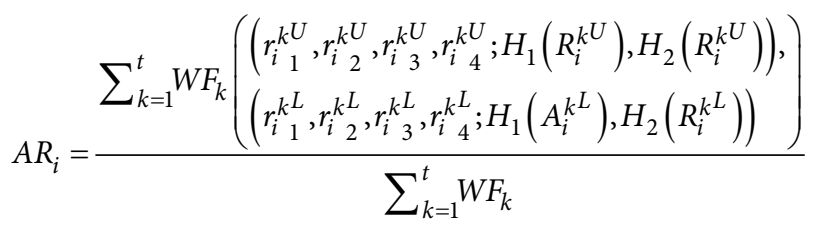


10. Rank the IT2FNs by following these sub-steps:

10.1. Set the ideal solution as $\widetilde{\widetilde{X}}_{\max }$ and the negative ideal solution as $\widetilde{\widetilde{X}}_{\min }$.

10.2. Figure out the distance based degree of similarity between each one of $A R_{i}$ and the positive interval type-2 fuzzy ideal solution $\left(d_{i}^{+}\right)$by utilizing Eq. (42):

$d_{i}^{+}\left(\widetilde{\widetilde{A}}_{i}, \widetilde{\widetilde{X}}_{\max }\right)=$

$$
\sqrt{\sum_{p=1}^{4}\left(r_{i 1}^{k^{U}}{ }_{p}^{U}-x_{i}^{U}\right)^{2}+\sum_{p=1}^{4}\left(r_{i 1}^{k} U_{p}^{L}-x_{i}^{L}\right)^{2}+}
$$

10.3. Calculate the distance based degree of similarity between each value of $A R_{i}$ and the negative ideal solution $\left(d_{i}^{-}\right)$by applying Eq. (43):

$d_{i}^{-}\left(\widetilde{\widetilde{A}}_{i}, \widetilde{\widetilde{X}}_{\min }\right)=$

$$
\sqrt{\sum_{p=1}^{4}\left(r_{i 1}^{k{ }^{U}}{ }_{p}^{U}-x_{i}^{U}\right)^{2}+\sum_{p=1}^{4}\left(r_{i}^{k^{U}{ }_{1}^{L}}-x_{i}^{L}\right)^{2}+} .
$$

10.4. Determine the value of FR by using the following (Kuo, 2017):

$$
F R_{i}=w^{-}\left(\frac{D_{i}^{-}}{\sum_{i=1}^{m} D_{i}^{-}}\right)+w^{+}\left(\frac{D_{i}^{+}}{\sum_{i=1}^{m} D_{i}^{+}}\right), i=1,2, \ldots, m .
$$

where: $w^{+}$and $w^{-}$denote the importance of distance from ideal positive and negative ideal solutions. It is worth mentioning that $w^{-}+w^{+}=1$ and $0<w^{-}<1,0<w^{+}<1$.

10.5. Rank the values of $F R_{i}$ in decreasing order of $F R_{i}$.

\section{Case study}

In this section to demonstrate the application steps of the introduced approach in real-world problems, an existing sustainable infrastructure project evaluation and selection problem in the literature (Mohagheghi, Mousavi, Aghamohagheghi, \& Vahdani, 2017b) is adopted and solved by using the presented method. Additionally, the case deals with selecting infrastructure projects in a multi-criteria process. Since project management deals with uncertainty, this process is under IT2F uncertainty. To reach the strategic goals, it is first vital to find the right projects. Therefore, the effectiveness of the decision relies on the decision-making process. After finding the right project, efficient implementation of the project relies on the project manager and project management tools.

The firm is given four candidates. Since the investment funds are narrow, the firm desires to find the most proper candidate project to supply and implement. Four candi- date projects are denoted as $A_{1}, A_{2}, A_{3}$ and $A_{4}$. Three DMs have expressed their opinions. They are referred to as $E_{1}$, $E_{2}$ and $E_{3}$. Tables 1 and 2 display the linguistic variables and their corresponding IT2FNs. Tables 3 and 4 depict the gathered judgments.

The criteria utilized for this evaluation process are as follows: The benefit criteria involves $C_{1}$ (Return on investment), $C_{3}$ (cost cutting), $C_{4}$ (Security), $C_{5}$ (Affordability), $C_{6}$ (Employment), $C_{7}$ (Essential accessibility), $C_{8}$ (Greenhouse gas discharges), $C_{9}$ (Climate and global warming) and $C_{10}$ (Capital performance). On the other hand, $C_{2}$ (Financial risk) is a cost criterion.

Table 1 . The linguistic variables used in rating

\begin{tabular}{|l|c|}
\hline Linguistic variables & Equivalent IT2F numbers \\
\hline Very poor (VP) & $((0,0,0,1 ; 1,1),(0,0,0,0.5 ; 0.9,0.9))$ \\
\hline Poor $(\mathrm{P})$ & $((0,1,1,3 ; 1,1),(0.5,1,1,2 ; 0.9,0.9))$ \\
\hline Meduim poor $(\mathrm{MP})$ & $((1,3,3,5 ; 1,1),(2,3,3,4 ; 0.9,0.9))$ \\
\hline Fair $(\mathrm{F})$ & $((3,5,5,7 ; 1,1),(4,5,5,6 ; 0.9,0.9))$ \\
\hline Meduim good (MG) & $((5,7,7,9 ; 1,1),(6,7,7,8 ; 0.9,0.9))$ \\
\hline Good $(\mathrm{G})$ & $((7,9,9,10 ; 1,1),(8,9,9,9.5 ; 0.9,0.9))$ \\
\hline Very good $(\mathrm{VG})$ & $((9,10,10,10 ; 1,1),(9.5,10,10,10 ; 0.9,0.9))$ \\
\hline
\end{tabular}

Table 2. The linguistic variables used in criteria weight assessment

\begin{tabular}{|l|c|}
\hline \multicolumn{1}{|c|}{$\begin{array}{c}\text { Linguistic } \\
\text { variables }\end{array}$} & Equivalent IT2F numbers \\
\hline Very poor (VP) & $((0,0,0,0.1 ; 1,1),(0,0,0,0.05 ; 0.9,0.9))$ \\
\hline Poor $(\mathrm{P})$ & $((0,0.1,0.1,0.3 ; 1,1),(0.05,0.1,0.1,0.2 ; 0.9,0.9))$ \\
\hline $\begin{array}{l}\text { Meduim poor } \\
\text { (MP) }\end{array}$ & $((0.1,0.3,0.3,0.5 ; 1,1),(0.2,0.3,0.3,0.4 ; 0.9,0.9))$ \\
\hline Fair $(\mathrm{F})$ & $((0.3,0.5,0.5,0.7 ; 1,1),(0.4,0.5,0.5,0.6 ; 0.9,0.9))$ \\
\hline $\begin{array}{l}\text { Meduim good } \\
\text { (MG) }\end{array}$ & $((0.5,0.7,0.7,0.9 ; 1,1),(0.6,0.7,0.7,0.8 ; 0.9,0.9))$ \\
\hline Good $(\mathrm{G})$ & $((0.7,0.9,0.9,1 ; 1,1),(0.8,0.9,0.9,0.95 ; 0.9,0.9))$ \\
\hline Very good $(\mathrm{VG})$ & $((0.9,1,1,1 ; 1,1),(0.95,1,1,1 ; 0.9,0.9))$ \\
\hline
\end{tabular}

To select the most proper project, the following is done:

1. Based on the values in Tables $1-4$, the decision matrix is formed.

2. The normalized decision matrix is made by means of Eqs (16)-(20). Table 5 displays the normalized values for the first DM.

3. The entropy of decision-making criteria is computed by using the following sub-steps:

3.1. The value of $\widetilde{\widetilde{U}}_{j}^{k}$ is obtained by using Eqs (21)-(23).

3.2. The value of $e n_{j}^{k}$ is obtained by using Eq. (24).

3.3. The degree of divergence ( $d i v_{j}^{k}$ ) is obtained by using Eq. (25).

3.4. Criteria weights are figured out by utilizing Eq. (26). Table 6 displays the values of $\widetilde{\widetilde{U}}_{j}^{k}$, $e n_{j}^{k}$, div ${ }_{j}^{k}$ and $E W_{j}^{K}$ for the first DM. 
Table 3. Gathered experts' judgments

\begin{tabular}{|c|c|c|c|c|c|}
\hline Criteria & Experts & $A_{1}$ & $A_{2}$ & $A_{3}$ & $A_{4}$ \\
\hline \multirow[t]{3}{*}{$C_{1}$} & $E_{1}$ & G & $F$ & VG & VG \\
\hline & $E_{2}$ & VG & G & G & G \\
\hline & $E_{3}$ & G & $\mathrm{F}$ & $\mathrm{G}$ & VG \\
\hline \multirow[t]{3}{*}{$C_{2}$} & $E_{1}$ & $\mathrm{~F}$ & $\mathrm{MG}$ & MG & $\mathrm{F}$ \\
\hline & $E_{2}$ & MG & $\mathrm{F}$ & MG & MG \\
\hline & $E_{3}$ & $\mathrm{~F}$ & $\mathrm{~F}$ & $\mathrm{~F}$ & MG \\
\hline \multirow[t]{3}{*}{$C_{3}$} & $E_{1}$ & G & MP & MP & VG \\
\hline & $E_{2}$ & MG & $\mathrm{F}$ & $\mathrm{F}$ & G \\
\hline & $E_{3}$ & $F$ & MP & G & VG \\
\hline \multirow[t]{3}{*}{$C_{4}$} & $E_{1}$ & VG & G & G & MP \\
\hline & $E_{2}$ & VG & $\mathrm{F}$ & MG & $\mathrm{P}$ \\
\hline & $E_{3}$ & $\mathrm{VG}$ & $\mathrm{MG}$ & $\mathrm{MG}$ & $\mathrm{MP}$ \\
\hline \multirow[t]{3}{*}{$C_{5}$} & $E_{1}$ & MP & MP & MG & G \\
\hline & $E_{2}$ & $\mathrm{~F}$ & MP & $\mathrm{F}$ & $\mathrm{G}$ \\
\hline & $E_{3}$ & $\mathrm{~F}$ & F & MP & MG \\
\hline \multirow[t]{3}{*}{$C_{6}$} & $E_{1}$ & MP & $\mathrm{P}$ & $\mathrm{F}$ & $\mathrm{VG}$ \\
\hline & $E_{2}$ & $\mathrm{MP}$ & $\mathrm{P}$ & MP & G \\
\hline & $E_{3}$ & $\mathrm{~F}$ & MP & $\mathrm{F}$ & $\mathrm{VG}$ \\
\hline \multirow[t]{3}{*}{$C_{7}$} & $E_{1}$ & G & G & G & $\mathrm{VG}$ \\
\hline & $E_{2}$ & $\mathrm{G}$ & MG & VG & G \\
\hline & $E_{3}$ & MG & MG & G & VG \\
\hline \multirow[t]{3}{*}{$C_{8}$} & $E_{1}$ & VG & MP & $\mathrm{F}$ & $\mathrm{VP}$ \\
\hline & $E_{2}$ & VG & $\mathrm{F}$ & MG & $\mathrm{VP}$ \\
\hline & $E_{3}$ & $\mathrm{VG}$ & MP & $\mathrm{F}$ & $\mathrm{P}$ \\
\hline \multirow[t]{3}{*}{$C_{9}$} & $E_{1}$ & G & MP & $\mathrm{F}$ & $\mathrm{P}$ \\
\hline & $E_{2}$ & $\mathrm{VG}$ & MP & $\mathrm{G}$ & $\mathrm{MP}$ \\
\hline & $E_{3}$ & VG & $\mathrm{F}$ & G & $\mathrm{P}$ \\
\hline \multirow[t]{3}{*}{$C_{10}$} & $E_{1}$ & $\mathrm{VG}$ & $\mathrm{F}$ & $\mathrm{G}$ & $\mathrm{VP}$ \\
\hline & $E_{2}$ & VG & MG & MG & $\mathrm{VP}$ \\
\hline & $E_{3}$ & G & $\mathrm{F}$ & G & $\mathrm{P}$ \\
\hline
\end{tabular}

Table 4. The weight vector of attributes

\begin{tabular}{|c|c|c|c|}
\hline \multirow{2}{*}{ Criteria } & \multicolumn{3}{|c|}{ Experts } \\
\cline { 2 - 4 } & $E_{1}$ & $E_{2}$ & $E_{3}$ \\
\hline$C_{1}$ & $\mathrm{VH}$ & $\mathrm{VH}$ & $\mathrm{VH}$ \\
\hline$C_{2}$ & $\mathrm{MH}$ & $\mathrm{H}$ & $\mathrm{VH}$ \\
\hline$C_{3}$ & $\mathrm{ML}$ & $\mathrm{M}$ & $\mathrm{ML}$ \\
\hline$C_{4}$ & $\mathrm{H}$ & $\mathrm{MH}$ & $\mathrm{H}$ \\
\hline$C_{5}$ & $\mathrm{ML}$ & $\mathrm{L}$ & $\mathrm{ML}$ \\
\hline$C_{6}$ & $\mathrm{H}$ & $\mathrm{H}$ & $\mathrm{MH}$ \\
\hline$C_{7}$ & $\mathrm{VL}$ & $\mathrm{L}$ & $\mathrm{L}$ \\
\hline$C_{8}$ & $\mathrm{M}$ & $\mathrm{ML}$ & $\mathrm{M}$ \\
\hline$C_{9}$ & $\mathrm{~L}$ & $\mathrm{ML}$ & $\mathrm{L}$ \\
\hline$C_{10}$ & $\mathrm{H}$ & $\mathrm{VH}$ & $\mathrm{VH}$ \\
\hline
\end{tabular}

Table 5. Normalized Judgments for the first DM

\begin{tabular}{|c|c|}
\hline Criteria & $A_{1}$ \\
\hline$C_{1}$ & $((0.7,0.9,9,1 ; 1,1),(0.8,0.9,0.9,0.95 ; 0.9,0.9))$ \\
\hline$C_{2}$ & $((0.4,0.6,0.6,1 ; 1,1),(0.5,0.6,0.6,0.75 ; 0.9,0.9))$ \\
\hline$C_{3}$ & $((0.7,0.9,0.9,1 ; 1,1),(0.8,0.9,0.9,0.95 ; 0.9,0.9))$ \\
\hline$C_{4}$ & $((0.9,1,1,1 ; 1,1),(0.95,1,1,1 ; 0.9,0.9))$ \\
\hline$C_{5}$ & $((0.1,0.3,0.3,0.5 ; 1,1),(0.2,0.3,0.3,0.4 ; 0.9,0.9))$ \\
\hline$C_{6}$ & $((0.1,0.3,0.3,0.5 ; 1,1),(0.2,0.3,0.3,0.4 ; 0.9,0.9))$ \\
\hline$C_{7}$ & $((0.7,0.9,0.9,1 ; 1,1),(0.8,0.9,0.9,0.95 ; 0.9,0.9))$ \\
\hline$C_{8}$ & $((0.9,1,1,1 ; 1,1),(0.95,1,1,1 ; 0.9,0.9))$ \\
\hline$C_{9}$ & $((0.7,0.9,0.9,1 ; 1,1),(0.8,0.9,0.9,0.95 ; 0.9,0.9))$ \\
\hline$C_{10}$ & $((0.9,1,1,1 ; 1,1),(0.95,1,1,1 ; 0.9,0.9))$ \\
\hline Criteria & $A_{2}$ \\
\hline$C_{1}$ & $((0.3,0.5,0.5,0.7 ; 1,1),(0.4,0.5,0.5,0.6 ; 0.9,0.9))$ \\
\hline$C_{2}$ & $((0.3,0.4,0.4,0.6 ; 1,1),(0.37,0.4,0.4,0.5 ; 0.9,0.9))$ \\
\hline$C_{3}$ & $((0.1,0.3,0.3,0.5 ; 1,1),(0.2,0.3,0.3,0.4 ; 0.9,0.9))$ \\
\hline$C_{4}$ & $((0.7,0.9,0.9,1 ; 1,1),(0.8,0.9,0.9,0.95 ; 0.9,0.9))$ \\
\hline$C_{5}$ & $((0.1,0.3,0.3,0.5 ; 1,1),(0.2,0.3,0.3,0.4 ; 0.9,0.9))$ \\
\hline$C_{6}$ & $((0,0.1,0.1,0.3 ; 1,1),(0.05,0.1,0.1,0.2 ; 0.9,0.9))$ \\
\hline$C_{7}$ & $((0.7,0.9,0.9,1 ; 1,1),(0.8,0.9,0.9,0.95 ; 0.9,0.9))$ \\
\hline$C_{8}$ & $((0.1,0.3,0.3,0.5 ; 1,1),(0.2,0.3,0.3,0.4 ; 0.9,0.9))$ \\
\hline$C_{9}$ & $((0.1,0.3,0.3,0.5 ; 1,1),(0.2,0.3,0.3,0.4 ; 0.9,0.9))$ \\
\hline$C_{10}$ & $((0.3,0.5,0.5,0.7 ; 1,1),(0.4,0.5,0.5,0.6 ; 0.9,0.9))$ \\
\hline Criteria & $A_{3}$ \\
\hline$C_{1}$ & $((0.9,1,1,1 ; 1,1),(0.95,1,1,1 ; 0.9,0.9))$ \\
\hline$C_{2}$ & $((0.3,0.4,0.4,0.6 ; 1,1),(0.37,0.4,0.4,0.5 ; 0.9,0.9))$ \\
\hline$C_{3}$ & $((0.1,0.3,0.3,0.5 ; 1,1),(0.2,0.3,0.3,0.4 ; 0.9,0.9))$ \\
\hline$C_{4}$ & $((0.7,0.9,0.9,1 ; 1,1),(0.8,0.9,0.9,0.95 ; 0.9,0.9))$ \\
\hline$C_{5}$ & $((0.5,0.7,0.7,0.9 ; 1,1),(0.6,0.7,0.7,0.8 ; 0.9,0.9))$ \\
\hline$C_{6}$ & $((0.3,0.5,0.5,0.7 ; 1,1),(0.4,0.5,0.5,0.6 ; 0.9,0.9))$ \\
\hline$C_{7}$ & $((0.7,0.9,0.9,1 ; 1,1),(0.8,0.9,0.9,0.95 ; 0.9,0.9))$ \\
\hline$C_{8}$ & $((0.3,0.5,0.5,0.7 ; 1,1),(0.4,0.5,0.5,0.6 ; 0.9,0.9))$ \\
\hline$C_{9}$ & $((0.3,0.5,0.5,0.7 ; 1,1),(0.4,0.5,0.5,0.6 ; 0.9,0.9))$ \\
\hline$C_{10}$ & $((0.7,0.9,0.9,1 ; 1,1),(0.8,0.9,0.9,0.95 ; 0.9,0.9))$ \\
\hline Criteria & $A_{4}$ \\
\hline$C_{1}$ & $((0.9,1,1,1 ; 1,1),(0.95,1,1,1 ; 0.9,0.9))$ \\
\hline$C_{2}$ & $((0.4,0.6,0.6,1 ; 1,1),(0.5,0.6,0.6,0.75 ; 0.9,0.9))$ \\
\hline$C_{3}$ & $((0.9,1,1,1 ; 1,1),(0.95,1,1,1 ; 0.9,0.9))$ \\
\hline$C_{4}$ & $((0.1,0.3,0.3,0.5 ; 1,1),(0.2,0.3,0.3,0.4 ; 0.9,0.9))$ \\
\hline$C_{5}$ & $((0.7,0.9,0.9,1 ; 1,1),(0.8,0.9,0.9,0.95 ; 0.9,0.9))$ \\
\hline$C_{6}$ & $((0.9,1,1,1 ; 1,1),(0.95,1,1,1 ; 0.9,0.9))$ \\
\hline$C_{7}$ & $((0.9,1,1,1 ; 1,1),(0.95,1,1,1 ; 0.9,0.9))$ \\
\hline$C_{8}$ & $((0,0,0,0.1 ; 1,1),(0,0,0,0.05 ; 0.9,0.9))$ \\
\hline$C_{9}$ & $((0,0.1,0.1,0.3 ; 1,1),(0.05,0.1,0.1,0.2 ; 0.9 .0 .9))$ \\
\hline$C_{10}$ & $((0,0,0,0.1 ; 1,1),(0,0,0,0.05 ; 0.9,0.9))$ \\
\hline
\end{tabular}


Table 6. The values obtained in giving weights of decision-making criteria

\begin{tabular}{|c|c|c|c|c|}
\hline Criteria & $\widetilde{U}_{j}^{k}$ for $A_{1}$ & $e n_{j}^{k}$ & $d i v_{j}^{k}$ & $E W_{j}^{K}$ \\
\hline$C_{1}$ & $(0.146,0.118)$ & $(0.05298,0.4059)$ & $(0.4702,0.594)$ & 0.2134 \\
\hline$C_{2}$ & $(0.208,0.228)$ & $(0.9899,0.9972)$ & $(0.0101,0.0028)$ & 0.0028 \\
\hline$C_{3}$ & $(0.161,0.135)$ & $(0.84,0.7864)$ & $(0.1599,0.2144)$ & 0.0748 \\
\hline$C_{4}$ & $(0.057,0.034)$ & $(0.837,0.7621)$ & $(0.163,0.2379)$ & 0.0797 \\
\hline$C_{5}$ & $(0.294,0.301)$ & $(0.9614,0.945)$ & $(0.03863,0.05499)$ & 0.0186 \\
\hline$C_{6}$ & $(0.273,0.273)$ & $(0.7326,0.669)$ & $(0.267,0.3307)$ & 0.1201 \\
\hline$C_{7}$ & $(0.306,0.314)$ & $(0.933,0.9045)$ & $(0.0667,0.0954)$ & 0.0323 \\
\hline$C_{8}$ & $(0.033,0.017)$ & $(0.6281,0.5524)$ & $(0.372,0.4476)$ & 0.1648 \\
\hline$C_{9}$ & $(0.102,0.082)$ & $(0.8259,0.774)$ & $(0.174,0.2259)$ & 0.0801 \\
\hline$C_{10}$ & $(0.04,0.021)$ & $(0.5298,0.4059)$ & $(0.4702,0.5941)$ & 0.2134 \\
\hline
\end{tabular}

Table 7. The value of $\widetilde{\widetilde{N W}}_{j}^{k}$

\begin{tabular}{|c|c|}
\hline Criteria & $\widetilde{\widetilde{N W}}_{j}^{k}$ \\
\hline$C_{1}$ & $((0.19,0.21,0.21,0.21 ; 1,1),(0.2,0.21,0.21,0.21 ; 0.39,0.39))$ \\
\hline$C_{2}$ & $((0.001,0.002,0.002,0.0025 ; 1,1),(0.0017,0.002,0.002,0.0022 ; 0.006,0.006)$ \\
\hline$C_{3}$ & $((0.007,0.022,0.022,0.037 ; 1,1),(0.015,0.022,0.022,0.03 ; 0.16,0.16)$ \\
\hline$C_{4}$ & $((0.056,0.072,0.072,0.08 ; 1,1),(0.064,0.072,0.072,0.076 ; 0.17,0.17))$ \\
\hline$C_{5}$ & $((0.0019,0.0056,0.0056,0.0093 ; 1,1),(0.0037,0.0056,0.0056,0.0074 ; 0.042,0.042))$ \\
\hline$C_{6}$ & $((0.084,0.11,0.11,0.12 ; 1,1),(0.096,0.11,0.11,0.114 ; 0.24,0.24))$ \\
\hline$C_{7}$ & $((0,0,0,0.003 ; 1,1),(0,0,0,0.0016 ; 0.072,0.072))$ \\
\hline$C_{8}$ & $((0.049,0.0824,0.0824,0.11 ; 1,1),(.066,0.082,0.082,0.099 ; 0.32,0.32))$ \\
\hline$C_{9}$ & $((0,0.008,0.008,0.024 ; 1,1),(0.004,0.008,0.008,0.016 ; 0.17,0.17))$ \\
\hline$C_{10}$ & $(0.15,0.192,0.192,0.213 ; 1,1),(0.17,0.192,0.192,0.2027 ; 0.388,0.388))$ \\
\hline
\end{tabular}

Table 8. The values of $S_{i, \text { ratio system }}^{k}, S_{\text {Copras }}^{k}$ and $R_{i}^{k}$

\begin{tabular}{|c|c|c|c|}
\hline & $S_{i, \text { ratio system }}^{k}$ & $S_{\text {Copras }}^{k}$ & $R_{i}^{k}$ \\
\hline $\mathrm{A}_{1}$ & $((0.37,0.6,0.6,0.75 ; 1,1)$, & $((0.12,0.24,0.24,0.4 ; 1,1)$, & $((0.25,042,0.42,0.58 ; 1,1)$, \\
& $(0.48,0.6,0.6,0.67 ; 0.87,0.87))$ & $(0.17,0.24,0.24,0.31 ; 0.06,0.06))$ & $(0.33,0.42,0.42,0.49 ; 0.65,0.65))$ \\
\hline $\mathrm{A}_{2}$ & $((0.14,0.31,0.31,0.51 ; 1,1)$, & $((0.05,0.12,0.12,0.26 ; 1,1)$, & $((0.09,0.21,0.21,0.39 ; 1,1)$, \\
& $(0.22,0.31,0.31,0.41 ; 0.87,0.87))$ & $(0.07,0.12,0.12,0.18 ; 0.058,0.058))$ & $(0.15,0.21,0.21,0.29 ; 0.65,0.65))$ \\
\hline $\mathrm{A}_{3}$ & $((0.36,0.56,0.56,0.72 ; 1,1)$, & $((0.11,0.21,0.21,0.38 ; 1,1)$, & $((0.23,0.39,0.39,0.55 ; 1,1)$, \\
& $(0.45,0.56,0.56,0.63 ; 0.87,0.87))$ & $(0.16,0.21,0.21,0.28 ; 0.06,0.06))$ & $(0.3,0.39,0.39,0.46 ; 0.65,0.65))$ \\
\hline $\mathrm{A}_{4}$ & $((0.26,0.37,0.37,0.46 ; 1,1)$, & $((0.08,014,0.14,0.24 ; 1,1)$, & $((0.17,0.25,0.25,0.35 ; 1,1)$, \\
& $(0.31,0.37,0.37,0.41 ; 0.87,0.87))$ & $(0.11,0.14,0.14,0.18 ; 0.06,0.06))$ & $(0.21,0.25,0.25,0.3 ; 0.65,0.65))$ \\
\hline
\end{tabular}

Table 9. The weight of each DM

\begin{tabular}{|c|c|c|c|}
\hline & $\mathrm{DM}_{1}$ & $\mathrm{DM}_{2}$ & $\mathrm{DM}_{3}$ \\
\hline$W F_{k}$ & 0.3359 & 0.3224 & 0.3418 \\
\hline
\end{tabular}

Table 10. The values of $A R_{i}$

\begin{tabular}{|l|l|}
\hline & \multicolumn{1}{|c|}{ Aggregate the decision matrixes } \\
\hline$A R_{1}$ & $((0.22,0.37,0.37,0.53 ; 1,1),(0.29,0.37, .37,0.44 ; 0.65,0.65))$ \\
\hline$A R_{2}$ & $((0.09,0.21,0.21,0.38 ; 1,1),(0.14,0.21,0.21,0.28 ; 0.65,0.65))$ \\
\hline$A R_{3}$ & $((0.17,0.32,0.32,0.5 ; 1,1),(0.24,0.32,0.32,0.4 ; 0.65,0.65))$ \\
\hline$A R_{4}$ & $((0.11,0.19,0.19,0.31 ; 1,1),(0.15,0.19,0.19,0.24 ; 0.65,65))$ \\
\hline
\end{tabular}


4. The value of $\widetilde{\widetilde{N W}}_{j}^{k}$ is obtained by using Eq. (27). Table 7 displays the results for the first DM.

5 . The ration system approach is used by applying Eqs (28)-(30).

6. The COPRAS based index presented in Eq. (31) is used to rank the alternatives.

7. The aggregated rankings are obtained by means of Eq. (32). Table 8 presents the values of $S_{i, \text { ratio system }}^{k}$, $S_{\text {Copras }}^{k}$ and $R_{i}^{k}$ for the first DM.

8. The weight of each DM is obtained by following these sub-steps:

8.1. The finest decision $\left(F D^{*}\right)$, the left negative finest decision $\left(F D_{l}^{-}\right)$and the right negative finest decision $\left(F D_{r}^{-}\right)$are computed by employing Eqs (33)-(36).

8.2. The values of $D I J_{k}^{*}, D I J_{l k}^{-}$and $D I J_{l r}^{-}$are computed by using Eqs (36)-(38).

8.3. The value of $I J C C_{k}$ is obtained by using Eq. (39).

8.4. The weight of each DM is figured out by utilizing Eq. (40). Table 9 depicts the weight of each DM.

9. The final ranking scores of each DM are aggregated by using Eq. (41). Table 10 displays the scores. Since the obtained values are IT2FNs, a ranking process is required that is applied in step 10.

10. The final ranking is obtained by following these sub steps:

10.1. The positive ideal solution $\left(\widetilde{\widetilde{X}}_{\max }\right)$ and the negative ideal solution $\left(\widetilde{\widetilde{X}}_{\min }\right)$ are defined.

10.2. Eq. (42) is utilized to compute the distance based value of similarity between $A R_{i}$ and the positive ideal solution $\left(d_{i}^{+}\right)$.

10.3. Eq. (43) is applied to gain the distance based value of similarity between $A R_{i}$ and the negative ideal solution $\left(d_{i}^{-}\right)$.

10.4. $F R_{i}$ is obtained by using Eq. (44).

10.5. Finally, the alternatives are ranked in decreasing order of $F R_{i}$. The results show that $\mathrm{A}_{1}$ is the best alternative. On the other hand, $\mathrm{A}_{4}$ is the worst alternative.

\section{Discussion of results}

To evaluate the results obtained in this method, a comparison with the study of Mohagheghi et al. (2017b) is carried out. Table 11 presents the values obtained by the method and the values existing in the original paper. The similarity of the results presents that the method provides reliable outcomes. In other words, the outcome depicts that this approach can be profitably utilized in real-world project selection problems. Moreover, this method can obtain the importance of decision makers and the selection criteria from the gathered judgments. This method applies IT2FSs that can better express uncertainty. In other words, this method is able to convey more uncertainty and as a result is more capable of dealing with today's decision making situations which are highly uncertain environments. Ad- ditionally, to better address uncertainty, defuzzification is done in later parts of the method. Another advantage in this method is that the aggregation process is carried out in the last steps of the process.

Table 11. The final rankings

\begin{tabular}{|c|c|c|c|}
\hline Alternative & $\begin{array}{c}\text { Mohagheghi } \\
\text { et al. (2017b) }\end{array}$ & $\mathrm{FR}_{\mathrm{i}}$ & $\begin{array}{c}\text { Proposed } \\
\text { Ranking }\end{array}$ \\
\hline $\mathrm{A}_{1}$ & 0.37 & 0.253 & 1 \\
\hline $\mathrm{A}_{2}$ & -0.08 & 0.249 & 3 \\
\hline $\mathrm{A}_{3}$ & 0.2 & 0.252 & 2 \\
\hline $\mathrm{A}_{4}$ & -0.11 & 0.244 & 4 \\
\hline
\end{tabular}

Furthermore, the sensitivity analysis is done based on the DMs' judgments. As a matter of fact, the proposed method for obtaining the weights of DMs is removed. Consequently, the weights of DMs are considered equal. The results are presented in Table 12. As seen, the rankings have changed. This issue illustrates the importance of determining the weights of DMs.

Table 12. Importance of DMs' weights

\begin{tabular}{|c|c|c|c|}
\hline $\begin{array}{c}\text { Solved without } \\
\text { DMs' weighting } \\
\text { method }\end{array}$ & Ranking & $\begin{array}{c}\text { Proposed } \\
\text { method }\end{array}$ & Ranking \\
\hline 0.252787 & 2 & 0.253 & 1 \\
\hline 0.250222 & 3 & 0.249 & 3 \\
\hline 0.252789 & 1 & 0.252 & 2 \\
\hline 0.244203 & 4 & 0.244 & 4 \\
\hline
\end{tabular}

\section{Conclusions}

In this paper, a novel project selection under interval type 2 fuzzy sets (IT2FSs) uncertainty was introduced. In order to address the importance of evaluation criteria, a method based on the concept of entropy was applied. To prevent loss of the gathered judgments, the introduced method utilized the last aggregation stance which applied the weight of DMs in its aggregation step. The importance of each DM was figured out by utilizing a novel method that used the gathered judgments to obtain the weight of each DM. Moreover, a new index for decision making was introduced that combined the advantages of the ratio system and the COPRAS method. To properly address uncertainty, defuzzification was done in the last step of the method through a new IT2F ranking method. To investigate the applicability and the real-world utilization of the presented MORAS method, an example focusing on sustainable infrastructure project selection was selected and solved. This demonstrated the appropriateness of the method in addition to showing that the method can better consider and interpret the obtained judgments and consequently can better address soft computing. The application showed that factors like uncertainty, importance of criteria and importance of decision makers (DMs) should be 
properly addressed. Moreover, the application presented the following primary results:

- Using IT2FSs to address uncertainty results in a better depiction of the vagueness in project environments.

- Applying MODAS results in a method that has the merits of the MOORA and the COPRAS method.

- Addressing the importance of decision-making criteria provides the method with useful information that enhances the effectiveness of the final decision.

- Given the nature of group decision-making methods, addressing the importance of decision makers in the process based on the gathered judgments improves the outcome of decision making.

However, there are some limitations that can be improved in future studies. One area of improvement is considering the impacts that evaluation criteria have on each other. Applying the concept of methods, such as the analytic network process (ANP) in this method could lead to its improvement. Moreover, another area of development is providing a decision support system based on this model. This would improve the applicability of the presented method in sustainable decision-making processes. Finally, developing this method with applications of fuzzy stochastic sets can provide the method with the ability to address both stochastic and fuzzy uncertainties.

\section{References}

Akhavan, P., Barak, S., Maghsoudlou, H., \& Antuchevičienė, J. (2015). FQSPM-SWOT for strategic alliance planning and partner selection; case study in a holding car manufacturer company. Technological and Economic Development of Economy, 21(2), 165-185.

https://doi.org/10.3846/20294913.2014.965240

Amoozad Mahdiraji, H., Arzaghi, S., Stauskis, G., \& Zavadskas, E. K. (2018). A hybrid fuzzy BWM-COPRAS method for analyzing key factors of sustainable architecture. Sustainability, 10(5), 1626. https://doi.org/10.3390/su10051626

Atkinson, R., Crawford, L., \& Ward, S. (2006). Fundamental uncertainties in projects and the scope of project management. International Journal of Project Management, 24(8), 687-698. https://doi.org/10.1016/j.ijproman.2006.09.011

Brauers, W. K. M., \& Zavadskas, E. K. (2006). The MOORA method and its application to privatization in a transition economy. Control and Cybernetics, 35(2), 445. https://doi.org/10.1007/s00170-010-2972-0

Brauers, W. K. M., \& Zavadskas, E. K. (2010). Project management by MULTIMOORA as an instrument for transition economies. Technological and Economic Development of Economy, (1), 5-24. https://doi.org/10.3846/tede.2010.01

Brauers, W. K., Zavadskas, E. K., Turskis, Z., \& Antucheviciene, J. (2006). Evaluating redevelopment alternatives of buildings with an application of the MOORA method. Simulation and Optimisation in Business and Industry, 131-135. Retrieved from http://hdl.handle.net/10067/599440151162165141

Chakraborty, S. (2011). Applications of the MOORA method for decision making in manufacturing environment. The International Journal of Advanced Manufacturing Technology, 54(912), 1155-1166. https://doi.org/10.1007/s00170-010-2972-0
Chatterjee, P., Athawale, V. M., \& Chakraborty, S. (2011). Materials selection using complex proportional assessment and evaluation of mixed data methods. Materials \& Design, 32(2), 851-860. https://doi.org/10.1016/j.matdes.2010.07.010

Chen, S. M., \& Lee, L. W. (2010). Fuzzy multiple attributes group decision-making based on the ranking values and the arithmetic operations of interval type-2 fuzzy sets. Expert Systems with Applications, 37(1), 824-833.

https://doi.org/10.1016/j.eswa.2009.06.094

Chiao, K. P. (2014, November). Interval type-2 fuzzy sets extension of analytic hierarchy process with application to new product development project screening. In IEEE 2014 International Conference on Fuzzy Theory and Its Applications (iFUZZY), (pp. 111-116).

https://doi.org/10.1109/iFUZZY.2014.7091242

Davoudabadi, R., Mousavi, S. M., Šaparauskas, J., \& Gitinavard, H. (2019). Solving construction project selection problem by a new uncertain weighting and ranking based on compromise solution with linear assignment approach. Journal of Civil Engineering and Management, 25(3), 241-251. https://doi.org/10.3846/jcem.2019.8656

Dorfeshan, Y., Mousavi, S. M., Mohagheghi, V., \& Vahdani, B., (2018). Selecting project-critical path by a new interval type2 fuzzy decision methodology based on MULTIMOORA, MOOSRA and TPOP methods. Computers \& Industrial Engineering, 120, 160-178.

https://doi.org/10.1016/j.cie.2018.04.015

Dorfeshan, Y., \& Mousavi, S. M. (2019). A new interval type-2 fuzzy decision method with an extended relative preference relation and entropy to project critical path selection, International Journal of Fuzzy System Applications, 8(1), 19-47. https://doi.org/10.4018/IJFSA.2019010102

Ebrahiminejad, M., Shakeri, E., Ardeshir, A., \& Zarandi, M. F. (2018). An object-oriented model for construction method selection in buildings using fuzzy information. Energy and Buildings, 178, 228-241. https://doi.org/10.1016/j.enbuild.2018.08.002

Erdogan, S. A., Šaparauskas, J., \& Turskis, Z. (2019). A multicriteria decision-making model to choose the best option for sustainable construction management. Sustainability, 11(8), 2239. https://doi.org/10.3390/su11082239

Gitinavard, H., Foroozesh, N., Mousavi, S. M., \& Mohagheghi, V. (2018). Soft computing based on a selection index method with risk preferences under uncertainty: applications to construction industry, International Journal of Computational Systems Engineering, 4(4), 238-247.

https://doi.org/10.1504/IJCSYSE.2018.095576

Grady, C. A., He, X., \& Peeta, S. (2015). Integrating social network analysis with analytic network process for international development project selection. Expert Systems with Applications, 42(12), 5128-5138.

https://doi.org/10.1016/j.eswa.2015.02.039

Hafezalkotob, A., Hafezalkotob, A., Liao, H., \& Herrera, F. (2019). An overview of MULTIMOORA for multi-criteria decision-making: theory, developments, applications, and challenges. Information Fusion, 51, 145-177. https://doi.org/10.1016/j.inffus.2018.12.002

Haghighi, M. H., Mousavi, S. M., \& Mohagheghi, V. (2019). A new soft computing model based on linear assignment and linear programming technique for multidimensional analysis of preference with interval type-2 fuzzy sets. Applied Soft Computing, 77, 780-796.

https://doi.org/10.1016/j.asoc.2019.01.048 
Haghighi, M. H., Mousavi, S. M., Antucheviciene, J., \& Mohagheghi, V. (2019). A new analytical methodology to handle time-cost trade-off problem with considering quality loss cost under interval-valued fuzzy uncertainty. Technological and Economic Development of Economy, 25(2), 277-299. https://doi.org/10.3846/tede.2019.8422

Hsu, L. C. (2014). A hybrid multiple criteria decision-making model for investment decision making. Journal of Business Economics and Management, 15(3), 509-529. https://doi.org/10.3846/16111699.2012.722563

Hu, J., Zhang, Y., Chen, X., \& Liu, Y. (2013). Multi-criteria decision making method based on possibility degree of interval type-2 fuzzy number. Knowledge-Based Systems, 43, 21-29. https://doi.org/10.1016/j.knosys.2012.11.007

Kildienè, S., Kaklauskas, A., \& Zavadskas, E. K. (2011). COPRAS based comparative analysis of the European country management capabilities within the construction sector in the time of crisis. Journal of Business Economics and Management, 12(2), 417-434. https://doi.org/10.3846/16111699.2011.575190

Kiliç, M., \& Kaya, İ. (2015). Investment project evaluation by a decision making methodology based on type-2 fuzzy sets. Applied Soft Computing, 27, 399-410.

https://doi.org/10.1016/j.asoc.2014.11.028

Kivilä, J., Martinsuo, M., \& Vuorinen, L. (2017). Sustainable project management through project control in infrastructure projects. International Journal of Project Management, 35(6), 1167-1183. https://doi.org/10.1016/j.ijproman.2017.02.009

Kracka, M., Brauers, W. K. M., \& Zavadskas, E. K. (2015). Ranking heating losses in a building by applying the MULTIMOORA. Inzinerine Ekonomika-Engineering Economics, 21(4), 352-359.

Kuo, T. (2017). A modified TOPSIS with a different ranking index. European Journal of Operational Research, 260(1), 152160. https://doi.org/10.1016/j.ejor.2016.11.052

Liou, J. J., Tamošaitienė, J., Zavadskas, E. K., \& Tzeng, G. H. (2016). New hybrid COPRAS-G MADM Model for improving and selecting suppliers in green supply chain management. International Journal of Production Research, 54(1), 114-134. https://doi.org/10.1080/00207543.2015.1010747

Maity, S., \& Sil, J. (2009). Color Image Segmentation using Type2 FuzzySets. International Journal of Computer and Electrical Engineering, 1(3), 376-383.

https://doi.org/10.1109/ICELIE.2006.347211

Mathiyazhagan, K., Gnanavelbabu, A., \& Lokesh Prabhuraj, B. (2019). A sustainable assessment model for material selection in construction industries perspective using hybrid MCDM approaches. Journal of Advances in Management Research, 16(2), 234-259. https://doi.org/10.1108/JAMR-09-2018-0085

Mavrotas, G., Diakoulaki, D., \& Kourentzis, A. (2008). Selection among ranked projects under segmentation, policy and logical constraints. European Journal of Operational Research, 187(1), 177-192. https://doi.org/10.1016/j.ejor.2007.03.010

Mendel, J. M. (2003). Type-2 fuzzy sets: some questions and answers. IEEE Connections. Newsletter of the IEEE Neural Networks Society, 1, 10-13.

Mendel, J. M. (2007). Type-2 fuzzy sets and systems: an overview. Computational Intelligence Magazine, IEEE, 2(1), 20-29. https://doi.org/10.1109/MCI.2007.357235

Mendel, J. M., John, R., \& Liu, F. (2006). Interval type-2 fuzzy logic systems made simple. Fuzzy Systems, IEEE Transactions on, $14(6), 808-821$.

https://doi.org/10.1109/TFUZZ.2006.879986

Mohagheghi, V., Mousavi, S. M., \& Vahdani, B. (2016). A new multi-objective optimization approach for sustainable project portfolio selection: a real world application under intervalvalued fuzzy environment. Iranian Journal of Fuzzy Systems, 13(6), 41-68. https://doi.org/10.22111/IJFS.2016.2821

Mohagheghi, V., Mousavi, S. M., \& Vahdani, B. (2017a). Analyzing project cash flow by a new interval type-2 fuzzy model with an application to construction industry. Neural Computing and Applications, 28(11), 3393-3411.

https://doi.org/10.1007/s00521-016-2235-6

Mohagheghi, V., Mousavi, S. M., Aghamohagheghi, M., \& Vahdani, B. (2017b) A new approach of multi-criteria analysis for the evaluation and selection of sustainable transport investment projects under uncertainty: a case study. International Journal of Computational Intelligence Systems, 10(1), 605-626. https://doi.org/10.2991/ijcis.2017.10.1.41

Mohagheghi, V., Mousavi, S. M., Vahdani, B., \& Shahriari, M. R. (2017c). R\&D project evaluation and project portfolio selection by a new interval type- 2 fuzzy optimization approach. Neural Computing and Applications, 28(12), 38693888. https://doi.org/10.1007/s00521-016-2262-3

Moradi, N., Mousavi, S. M., \& Vahdani, B. (2018). An interval type-2 fuzzy model for project-earned value analysis under uncertainty. Journal of Multiple-Valued Logic and Soft Computing, 30, 79-103.

Mousavi, S. M. (2018). A new interval-valued hesitant fuzzy pairwise comparison-compromise solution methodology: an application to cross-docking location planning. Neural Computing and Applications, 1-15. https://doi.org/10.1007/s00521-018-3355-y

Mulliner, E., Smallbone, K., \& Maliene, V. (2013). An assessment of sustainable housing affordability using a multiple criteria decision making method. Omega, 41(2), 270-279. https://doi.org/10.1016/j.omega.2012.05.002

Oztaysi, B. (2015). A group decision making approach using interval Type-2 fuzzy AHP for enterprise information systems project selection. Multiple-Valued Logic and Soft Computing, 24(5-6), 475-500.

Parvaneh, F., \& El-Sayegh, S. M. (2016). Project selection using the combined approach of AHP and LP. Journal of Financial Management of Property and Construction, 21(1), 39-53. https://doi.org/10.1108/JFMPC-09-2015-0034

Pires, A. S., Ferreira, F. A., Jalali, M. S., \& Chang, H. C. (2018). Barriers to real estate investments for residential rental purposes: mapping out the problem. International Journal of Strategic Property Management, 22(3), 168-178. https://doi.org/10.3846/ijspm.2018.154

Rathi, R., Khanduja, D., \& Sharma, S. (2015). Six sigma project selection using fuzzy TOPSIS decision making approach. Management Science Letters, 5(5), 447-456. https://doi.org/10.5267/j.msl.2015.3.009

Sierra, L. A., Yepes, V., \& Pellicer, E. (2018). A review of multicriteria assessment of the social sustainability of infrastructures. Journal of Cleaner Production, 187, 496-513. https://doi.org/10.1016/j.jclepro.2018.03.022

Stanujkic, D., Magdalinovic, N., Stojanovic, S., \& Jovanovic, R. (2012). Extension of ratio system part of MOORA method for solving decision-making problems with interval data. Informatica, 23(1), 141-154.

Taillandier, F., Taillandier, P., Tepeli, E., Breysse, D., Mehdizadeh, R., \& Khartabil, F. (2015). A multi-agent model to manage risks in construction project (SMACC). Automation in Construction, 58, 1-18. https://doi.org/10.1016/j.autcon.2015.06.005

Tavana, M., Keramatpour, M., Santos-Arteaga, F. J., \& Ghorbaniane, E. (2015). A fuzzy hybrid project portfolio selection method using data envelopment analysis, TOPSIS and inte- 
ger programming. Expert Systems with Applications, 42(22), 8432-8444. https://doi.org/10.1016/j.eswa.2015.06.057

Umer, A., Hewage, K., Haider, H., \& Sadiq, R. (2016). Sustainability assessment of roadway projects under uncertainty using Green Proforma: an index-based approach. International Journal of Sustainable Built Environment, 5(2), 604-619. https://doi.org/10.1016/j.ijsbe.2016.06.002

Yue, Z. (2011). A method for group decision-making based on determining weights of decision makers using TOPSIS. Applied Mathematical Modelling, 35(4), 1926-1936. https://doi.org/10.1016/j.apm.2010.11.001

Zamri, N., \& Abdullah, L. (2013). A new linguistic variable in interval type-2 fuzzy entropy weight of a decision making method. Procedia Computer Science, 24, 42-53. https://doi.org/10.1016/j.procs.2013.10.026

Zavadskas, E. K., Kaklauskas, A., \& Sarka, V. (1994). The new method of multicriteria complex proportional assessment of projects. Technological and Economic Development of Economy, 1(3), 131-139.

Zavadskas, E. K., Kaklauskas, A., Turskis, Z., Tamosaitiene, J., \& Kalibatas, D. (2011). Assessment of the indoor environ- ment of dwelling houses by applying the COPRAS-G method: Lithuania case study. Environmental Engineering and Management Journal, 10(5), 637-647.

https://doi.org /10.30638/eemj.2011.087

Zhang, J., \& Yang, Y. (2018). The challenges of Yunnan's engagement on sustainable highway infrastructure project in the context of belt and road initiative. In 3rd International Symposium on Asian B\&R Conference on International Business Cooperation (ISBCD 2018). Atlantis Press.

Zolfaghari, S., \& Mousavi, S. M. (2018). Construction-project risk assessment by a new decision model based on De-Novo multi-approaches analysis and hesitant fuzzy sets under uncertainty. Journal of Intelligent and Fuzzy Systems, 35, 639-649. https://doi.org/10.3233/JIFS-162013

Zolfani, S. H., Pourhossein, M., Yazdani, M., \& Zavadskas, E. K. (2018). Evaluating construction projects of hotels based on environmental sustainability with MCDM framework. Alexandria Engineering Journal, 57(1), 357-365.

https://doi.org/10.1016/j.aej.2016.11.002 